Chapman University

Chapman University Digital Commons

9-9-2019

Nonbinding Goals in Teams: A Real Effort Coordination

Experiment

James Fan

Joaquin Gómez-Miñambres

Follow this and additional works at: https://digitalcommons.chapman.edu/esi_pubs

Part of the Economic Theory Commons, and the Other Economics Commons 


\section{Nonbinding Goals in Teams: A Real Effort Coordination Experiment}

\section{Comments}

This article was originally published in Manufacturing \& Service Operations Management, volume 22, issue 5, in 2020. https://doi.org/10.1287/msom.2019.0793

\section{Copyright}

This article was written and prepared by U.S. government employee(s) on official time and is therefore in the public domain. 


\title{
Nonbinding Goals in Teams: A Real Effort Coordination Experiment
}

\author{
James Fan, ${ }^{a}$ Joaquín Gómez-Miñambres ${ }^{\text {b,c }}$ \\ ${ }^{\mathbf{a}}$ Graduate School of Business and Public Policy, Naval Postgraduate School, Monterey, California 93943; ${ }^{\mathbf{b}}$ Department of Economics, \\ Lafayette College, Easton, Pennsylvania 18042; ${ }^{\mathbf{c}}$ Economic Science Institute, Chapman University, Orange, California 92866 \\ Contact: james.fan@nps.edu, (D) http://orcid.org/0000-0001-9827-7144 (JF); gomezmij@lafayette.edu (JG-M)
}

Received: August 15, 2017

Revised: June 15, 2018; November 15, 2018;

January 28, 2019; February 25, 2019

Accepted: February 27, 2019

Published Online in Articles in Advance:

September 9, 2019

https://doi.org/10.1287/msom.2019.0793

Copyright: This article was written and prepared by U.S. government employee(s) on official time and is therefore in the public domain

\begin{abstract}
Problem definition: We investigate the impact of nonbinding (wage-irrelevant) goals, set by a manager, on a team of workers with "weak-link" production technology. Can nonbinding goals improve team production when team members face production complementarity? Academic/practical relevance: Nonbinding goals are easy to implement and ubiquitous in practice. These goals have been shown to improve individual performance, but it remains to be seen if such goals are effective in team production when there is production complementarity among workers. Methodology: We first develop a theoretical model where goals act as reference points for workers' intrinsic motivation to complete the task. We then test our hypotheses in a controlled, human-subjects experiment. In our experiment, participants act as managers or workers, and we examine the impact of nonbinding goals on team outcomes. Results: Consistent with our model, we find evidence that team production does increase when managers are able to set goals. This effect is strongest when goals are challenging but attainable for weak-link workers. However, we also find evidence that many managers assign goals that are too challenging for weak-link workers, resulting in suboptimal team production, lower profits, and higher wasted performance (performance above the weak-link level). Managerial implications: Our analysis indicates that goals are effective motivators in teams, but some managers may have difficulty overcoming personal biases when setting goals. The task of setting team goals is more complex than setting individual goals, and many managers can benefit from training on how to set good goals for the team. Moreover, our finding that suboptimal goals also increase wasted performance suggests that improving goal-setting strategies is especially important in production settings where overperformance is costly for the firm (scrap, energy use, inventory costs, lower prices as a result of oversupply, etc.).
\end{abstract}

Funding: Pennsylvania State Laboratory of Economics, Management and Auctions provided some funding Supplemental Material: The online appendix is available at https://doi.org/10.1287/msom.2019.0793.

Keywords: behavioral operations $\cdot$ game theory $\cdot$ experiments

\section{Introduction}

Setting a goal that does not directly impact a worker's earnings is a ubiquitous motivational tool; a manager may have an informal celebration if an early deadline is met, send a congratulatory message when the project is completed, or keep a running tally of the number of days with no workplace accidents to encourage safety. Under standard utility theory, these goals, commonly called nonbinding goals, should have no impact on output, and hence, managers should not use them to motivate workers. However, nonbinding goals are seen everywhere in practice, and evidence from psychology (Deci 1971, Frey and Jegen 2001, Kamenica 2012) and managerial economics (Heath et al. 1999; Goerg and Kube 2012; Gómez-Miñambres 2012; Corgnet et al. 2015,2018 ) shows that nonbinding goals can be very effective motivators. Typically, a nonbinding goal can increase individual performance by $10 \%-30 \%$ in humansubject experiments. Furthermore, nonbinding goals are particularly attractive tools for managers because these goals are costless to implement. There is limited research on the impact of goals in teams, especially in more complex production settings, although evidence from operations management (Doerr et al. 1996, Linderman et. al 2006) suggests that binding and nonbinding goals can improve output for pull production and Six Sigma teams. Still, it is unclear whether nonbinding goals will be effective in production settings with complementarities, where team production depends on all workers exerting effort. For example, in project management, all team members must meet the deadline to avoid late delivery. In software development, developers code large software suites in pieces, and all developers must ensure that their portion of the code is bug-free before shipping the final product. In these settings, managers may only be able to set one goal for the whole team because of fairness concerns or unobservability of individual worker performance. When managers do not individualize the goal for each worker, and the production technology depends 
on all workers, it is unclear whether nonbinding goals are still effective.

Therefore, we look to answer the following questions: (1) Can nonbinding goals increase production in teams? And if so, (2) what goal should managers set to maximize production? In this paper, we show that nonbinding goals are powerful enough to motivate a team of workers to increase production, even when significant production complementarities exist. However, managers often set suboptimal goals for teams. We define a production setting where teams, consisting of one manager and three workers, must coordinate to increase team production; team production and monetary payoffs for everyone are determined by the minimum performance of all workers (i.e., the "weak link"). To capture the effect of nonmonetary incentives on the team, we allow managers to assign a nonbinding goal for team production. We use the weak-link production technology as a strong test for nonbinding goals. If nonbinding goals are effective in a team setting with the highest degree of complementarity, these goals should be even more effective for teams with less complementarity, where team production also depends on worker performance above the minimum.

Our research is motivated by extensive evidence of team coordination failure in weak-link production settings, with individual effort rapidly falling to the minimum level (see Camerer 2003 and Devetag and Ortmann 2007 for reviews). In particular, we contribute to the literature by studying how nonbinding, seemingly payoff-irrelevant goals affect team production with weak-link technology. From a theoretical standpoint, we modify the standard weak-link coordination game (Van Huyck et al. 1990) by assuming that workers have two sources of motivation: a standard monetary motivation that depends on the team production and a nonmonetary motivation that depends on whether the individual's performance is above or below the goal. As a result, a worker's utility depends not only on the standard monetary payoffs and cost of effort but also on whether he or she achieved the goal. In other words, even if producing more than the weak link does not entail monetary rewards, it does provide nonmonetary satisfaction for workers whose individual performance is above the goal. We show that when nonbinding goals are present, two types of workers characterize the solution of the game: a group of low-ability workers who match what the weak-link worker does and a group of highability workers who choose to produce above the weaklink level to garner the nonmonetary utility associated with goal attainment. Importantly, we also show that to maximize team production, a manager must set a goal that it is challenging but attainable for the weaklink worker and that the optimal goal minimizes high- ability workers' wasted performance (performance above the weak-link level), minimizing the spread of performance among team members.

To our knowledge, ours is the first paper to theoretically and experimentally examine the impact of nonbinding goals on team production with weak-link complementarity. We design a weak-link coordination game using a real effort laboratory experiment, and we allow managers to set a nonbinding goal for team production. We chose to use a laboratory experiment so that we could make causal inferences about the efficacy of nonbinding goals, as well as measure and control for heterogeneity in worker ability. Consistent with our predictions, we find that when managers are able to set goals for the team, team production increases by $19.8 \%$ on average, and as our model predicts, the positive effect of goal setting is especially strong when goals are challenging but attainable for the weak-link worker, whose performance determines team production. However, we also find that managers do not always set profit-maximizing goals for the team, indicating that managers may be setting goals for other reasons. In particular, we find evidence that managers often disregard the weak-link worker's ability, which leads some managers to assign unreasonably difficult goals for the weak-link worker. Finally, consistent with our theoretical results, we provide evidence that managers who assign unreasonable goals for the weak link generate not only lower team production but also higher wasted performance; this is, in part, because goals that are too difficult for the weak link are more motivational for higher-ability workers.

\subsection{Connection to the Literature}

Our research sits at the intersection of the goal-setting and the coordination in teams literature, which are well-studied topics in psychology, managerial economics, and, recently, operations management. In this section, we highlight the streams of literatures most relevant to our paper and detail our contributions. In the goal-setting literature, the motivational effect of wage-irrelevant goals has been studied at length in psychology (see Locke and Latham 2002 for a review). Psychologists have focused on the motivational and cognitive aspects of goals, stressing that goals should be SMART, an acronym for specific, measurable, attainable, relevant, and time-based. More recently, nonbinding goals have been studied in managerial economics and proven to be effective motivators for individual workers (Heath et al. 1999; Goerg and Kube 2012; Gómez-Miñambres 2012; Corgnet et al. 2015, 2018; Smithers 2015). Rather than relying on the monetary consequences of their actions, the goals considered in this literature appeal to the intrinsic motivation of workers (Deci 1971, Frey 
and Jegen 2001, Kamenica 2012). Although a growing number of papers in economics and management have documented the effectiveness of various forms of nonmonetary incentives on individual workers, including performance goals (Wu et al. 2008; Goerg and Kube 2012; Gómez-Miñambres 2012; Corgnet et al. 2015, 2018), personal goals in self-control setting (Ainslie 1992, Hsiaw 2013), status incentives (Charness et al. 2014), symbolic rewards (Kosfeld and Neckermann 2011), delegation (Fehr et al. 2013), autonomy (Falk and Kosfeld 2006), and trust (Dickinson and Villeval 2008), little is known about the effectiveness of nonmonetary incentives in teams. Contrary to the existing literature on goal setting, we focus on a team environment where the success or failure of a project relies on the performance of the weakest link. This is similar to the assembly-line context that Doerr et al. (1996) study, analyzing the impact of binding goals under push-versus-pull production policies. The authors find that these incentives have a positive impact on output under pull production. Our results show that nonbinding goals also have a positive effect on team production. The goals that we consider are nonbinding and hence cheaper and easier to implement in practice.

Our research is also motivated by extensive evidence of team coordination failure in weak-link games, with effort rapidly falling to the minimum level (see Camerer 2003 and Devetag and Ortmann 2007 for reviews). The study of weak-link (or minimum effort) games is common in the economics and operations literature (Van Huyck et al. 1990, Weber 2006, Brandts et al. 2011, Hyndman et al. 2014, Shokoohyar et al. 2017) because these games apply to many different production environments. Almost all of these studies are abstract effort experiments in the sense that they use the concept of induced valuation to create individual cost of effort (Smith 1976); if a subject selects effort level $x$, then he or she pays a certain amount $c(x)$ in experimental earnings. Furthermore, most of these experiments also induce symmetric costs of effort across the experimental subjects. These studies find that with large groups (three or more subjects), coordination outcomes often converge to the least efficient equilibrium (see Van Huyck et al. 1990, Knez and Camerer 1994, Brandts et al. 2011). External influences, such as pregame communication or intergroup competition, can induce better outcomes (Van Huyck et al. 1990, Cooper et al. 1992, Bornstein et al. 2002).

Coordination is a growing topic of research in operations management as well, because coordination failure can arise in team production environments such as supplier capacity allocation and project management. For example, Gerchak and Wang (2004) model how a set of suppliers coordinates when choosing production quantities to support assembly operations for a common customer. Argyres (1999) discusses the difficulty of coordination for the four suppliers of the B-2 Bomber program and the challenges of on-time delivery from a project management perspective. From an experimental point of view, studies have examined coordination outcomes in two-player newsvendor games (Hyndman et al. 2014), project management games where effort accumulates over stages (Shokoohyar et al. 2017), and group selection games where subjects decide whether to pay a membership fee (Fan et al. 2018). Again, these studies focus on abstract effort, which may not capture important psychological effects from the act of working (such as intrinsic motivation) that can affect coordination outcomes.

Real effort tasks (such as adding rows of numbers or counting coins) may more closely match actual team production, where the cost of effort is not symmetric among team members, and they have the added challenges that players' cost functions and the "optimal" coordination level are not directly observable. There are only a few real effort coordination experiments in the literature. The coordination experiment of Bortolotti et al. (2016) consists of assigning subjects to teams and having them sort and count coins worth 1 , 2,5 , and 10 euro cents within a time limit. The objective is to minimize the number of counting errors. As in our experiment, the task is individual, but the payoff to a team is the minimum of all team members. The authors find that subjects eventually coordinate at the efficient level of zero errors from all members. The second real effort coordination experiment was conducted by Vranceanu et al. (2015). The authors use the task of counting 7's in a block of random numberscorrectly reporting the number of 7's in a block generates one unit of output. Subjects are paired, and individual profit is a function of the minimum output as well as individual breaks taken, thought of as the opportunity cost of working. Higher-performing individuals can also punish their lower-performing counterparts. The study finds that team performance is not lower than individual performance, suggesting high levels of cooperation in pairs, and that the ability to sanction does not significantly improve team production.

The real effort activity in our experiment consists of a simple yet tedious slider task activity, first used by Gill and Prowse (2012), where individual effort is highly correlated with individual performance. Instead of relying on peer pressure or exogenously given goals, we consider the effect of nonbinding goals set by managers whose payoff depends on the team production. Thus, we contribute to the literature by introducing nonbinding goals as a potential mechanism to improve coordination for a group of workers facing high levels of strategic complementarity. Our findings indicate that (1) nonbinding goals can meaningfully 
improve team production, although the level of the goal is important, and that (2) real effort coordination outcomes can significantly differ from abstract effort coordination outcomes.

The rest of this paper proceeds as follows. In Section 2, we introduce our theoretical framework, and we model the potential impact of goals on worker performance and team production. Section 3 describes the experimental environment, procedures, and hypotheses. Main results are presented in Section 4, and Section 5 concludes.

\section{Model}

In this section, we develop a model of a weak-link coordination game where workers have asymmetric cost functions and intrinsic motivation, and we establish our experiment hypotheses.

\subsection{Setup}

In our model, one manager is in charge of a team of $n$ workers who must complete the project at hand. The effort of worker $i$ is given by $y_{i} \in \mathbb{R}_{+}$, and we denote by $\mathbf{y}=\left[y_{1}, \ldots, y_{n}\right]$ the vector of possible effort levels. We assume that a worker's performance in the project depends only on his or her exerted effort. Therefore, we use the terms effort and performance interchangeably in this paper (although in the online appendix we consider a model with variability of performance given the effort). We assume that workers have a different increasing, twice-differentiable, and strictly convex cost of effort functions $c\left(y ; \theta_{i}\right)$. We interpret parameter $\theta_{i}$ as worker $i$ 's ability level, with $\theta_{i} \in[\underline{\theta}, \bar{\theta}]$. Without loss of generality, we assume that $\theta_{1} \leq \theta_{2} \leq \cdots \leq \theta_{n}$, so $\theta_{1}$ is the ability of the weak-link worker. We abstract away from moral hazard concerns by assuming that ability is common knowledge to the manager and workers. We further assume that $c\left(0 ; \theta_{i}\right)=0$ for all $\theta_{i}$ and that

$$
c_{y}\left(y ; \theta_{n}\right) \leq c_{y}\left(y ; \theta_{n-1}\right) \leq \cdots \leq c_{y}\left(y ; \theta_{1}\right),
$$

where $c_{y}\left(y ; \theta_{i}\right)$ is the partial derivative of $c\left(y ; \theta_{i}\right)$ with respect to $y$.

Team production $M(\mathbf{y})$ is determined by the lowest performance of all workers, so $M(\mathbf{y})=\min \left(y_{1}, \ldots, y_{n}\right)$. For simplicity, we assume that all $n$ workers as well as the manager receive identical monetary payoffs based on $M(y)$, so the monetary payoffs are given by $A \cdot M(\mathbf{y})$, where $A>0$ reflects the profitability of the team production, and it hence determines the magnitude of the monetary team incentives. Workers may also be motivated by nonbinding goals assigned by the manager. We formalize this effect by considering a goal-dependent, nonmonetary value function $v\left(y_{i}-g\right)$ that satisfies the following prospect theoretic properties (Kahneman and Tversky 1979):

1. $v(0)=0$ (goal as a reference point);
2. $v^{\prime}(\cdot)>0$ (increase in production given a goal);

3. for all $x>0,-v(-x)=\lambda v(x)$, where $\lambda>1$ (goalinduced loss aversion);

4. $v^{\prime \prime}(x)>0$, for all $x<0$ (convexity for goalinduced losses); and

5. $v^{\prime \prime}(x)<0$, for all $x>0$ (concavity for goalinduced gains),

where $v^{\prime}(\cdot)$ and $v^{\prime \prime}(\cdot)$ denote the first and second derivatives of $v(\cdot)$, respectively. Our nonmonetary utility function is motivated by experimental and field evidence showing that wage-irrelevant goals serve as reference points in a manner that is consistent with prospect theory (Heath et al. 1999). Properties 4 and 5 capture a prospect theory principle commonly known as diminishing sensitivity, the idea that outcomes have a smaller marginal impact when they are more distant from the reference point. Diminishing sensitivity not only gives the value function its characteristic $S$ shape but also has been found to be the core explanation of the motivational effect of goals as reference points (Wu et al. 2008). Property 3 captures loss aversion, the property whereby losses loom larger than gains. Similar specifications have also been considered by other authors in economics and management literatures (Corgnet et al. 2015, 2018, Dalton et al. 2016).

A worker's payoff $\pi_{i}^{w}$ is the sum of monetary gains and nonmonetary utility minus the cost of effort:

$$
\pi_{i}^{w}\left(y_{i}, y_{-i}, g, A ; \theta_{i}\right)=A \cdot M(\mathbf{y})+v\left(y_{i}-g\right)-c\left(y_{i} ; \theta_{i}\right) .
$$

Note that we assume that a worker's nonmonetary utility function $v\left(y_{i}-g\right)$ is determined by his or her individual performance relative to the goal. (In the online appendix, we explore the case where $v(\cdot)$ depends on the difference between team production and the goal. We show that the results are equivalent to when only monetary incentives are present). Therefore, whereas a worker's monetary payoff depends only on the team production (as in the standard weaklink game), the worker gets an additional nonmonetary payoff when his or her performance meets or exceeds the goal. The last effect represents the satisfaction that a worker gets from his or her individual performance regardless of team production-in other words, from doing his or her part of the project.

Finally, we assume that the manager's payoff $\pi^{m}$ depends only on the production of the team project:

$$
\pi^{m}(\mathrm{~A}, \mathbf{y})=A \cdot M(\mathbf{y})
$$

Thus, the manager incurs no cost of effort because he or she does not participate in production, and his or her only objective is to maximize team production by choosing a nonbinding goal $g$ that maximizes his or her monetary payoffs.

We first examine the standard case with no goaldependent utility. Then we show the effects of 
including a nonmonetary, goal-dependent utility function.

\subsection{Coordination Game with Only Monetary Payoffs}

In the one-stage, asymmetric cost coordination game with only monetary motivation, a worker's payoff function is given by

$$
\pi_{i}^{w}\left(\mathrm{~A}, \mathbf{y}, y_{i}\right)=A \cdot M(\mathbf{y})-c\left(y_{i} ; \theta_{i}\right) .
$$

The first-order condition of worker $i$ 's payoff maximization function is $c_{y}\left(y_{i} ; \theta_{i}\right) \leq A$. The first-order condition will hold with equality if the agent is the weak-link worker as well as the only worker producing at the minimum, and it will be $c_{y}\left(y_{i} ; \theta_{i}\right)=0$ otherwise (note that when there is more than one worker producing at the minimum, the profit functions of these workers are kinked in $y_{i}$ ). Thus, when worker $i$ 's performance is above the minimum, there is no benefit to choose a higher performance because team production is determined by the minimum performance of the team. This insight helps build the intuition for Proposition 1. All proofs are relegated to the appendix.

Proposition 1. A vector of effort levels $y^{*}$ is a pure strategy Nash equilibrium to this game if and only if $y_{i}^{*}=y$ for all $i$, where $y \in[0, \tilde{y}]$, and $\tilde{y}$ is the solution to $c_{y}\left(\tilde{y} ; \theta_{1}\right)=A$.

Proposition 1 indicates that in equilibrium, workers' performance is determined by the worker with the lowest ability (or weak-link worker). Although y puts an upper bound on best-response choices of $y_{i}^{*}$, any team production level such that $y_{i}^{*} \leq \tilde{y}$ can be an equilibrium.

\subsection{Coordination Game with a Goal-Dependent Nonmonetary Utility}

We now study the effects of nonmonetary utility. In particular, we assume that the worker's payoff function is given by the combination of monetary and nonmonetary utilities as well as the cost of effort

$$
\pi_{i}^{w}\left(\mathrm{~A}, \mathbf{y}, y_{i}, g\right)=A \cdot M(\mathbf{y})+v\left(y_{i}-g\right)-c\left(y_{i} ; \theta_{i}\right) .
$$

As a reminder, team production $M(\mathbf{y})$ is determined by the lowest performance of all team members, so $M(\mathbf{y})=\min \left(y_{1}, \ldots, y_{n}\right)$. A worker's payoff maximization problem changes so that the first-order condition is characterized by $c_{y}\left(y_{i} ; \theta_{i}\right) \leq A+v^{\prime}\left(y_{i}-g\right)$. The left-hand side of this expression represents the marginal cost, and the right-hand side represents the marginal utility of effort, which again depends on team production. Let us define the variables $y\left(\theta_{i}, g\right)$ and $\bar{y}\left(\theta_{i}, g\right)$ to be the effort levels that solve a worker's maximization problem when he or she is not the weaklink worker and when he or she is, respectively. In Proposition 2, we show that in equilibrium, two groups of workers are formed: low-ability workers who choose the same effort level as the weak-link worker and high-ability workers whose goal-dependent marginal utility is high enough for them to choose an effort level above the minimum.

Proposition 2. Let us define $L\left(\theta_{1}, g\right)=\left\{i \in N \mid y\left(\theta_{i}, g\right) \leq\right.$ $\left.\bar{y}\left(\theta_{1}, g\right)\right\}$. A vector of effort levels $\boldsymbol{y}^{*}$ is a pure strategy Nash equilibrium if for all $i \in L\left(\theta_{1}, g\right), y_{i}^{*}=y$ and $y\left(\theta_{1}, g\right) \leq$ $y \leq \bar{y}\left(\theta_{1}, g\right)$. For all $i \notin L\left(\theta_{1}, g\right), y_{i}^{*}=\underline{y}\left(\theta_{i}, g\right)$.

Proposition 2 indicates that given a goal, there are potentially two groups of workers in equilibrium. The first group consists of low-ability workers who choose the same effort level as the weak-link worker, similar to the case with only monetary incentives in Proposition 1. This is because low-ability workers have a marginal cost of effort that is high relative to the marginal nonmonetary utility, and hence, in equilibrium, their strategies are affected by the team incentives $A$. Within this group, the set of best-response effort choices for all workers is determined by the ability of the weak-link worker, just as in the case with only monetary payoffs (Proposition 1). The second group consists of workers with a sufficiently high ability level who choose a level of effort that maximizes nonmonetary utility minus the cost of effort and hence is independent of the team incentives. For high-ability workers, the marginal cost of effort relative to the marginal goal-dependent nonmonetary utility is low enough for the workers to be motivated simply by the nonmonetary incentives derived from goal attainment. In this case, workers' strategies are independent of other workers' decisions and hence different from the case with solely monetary incentives. Therefore, one consequence of our model is that when workers derive a nonmonetary utility from their own individual performance, effort levels are actually less coordinated, because high-ability workers perform above team production in equilibrium.

To better understand the intuition behind this result, let us consider a simple example with $n=3$. On the one hand, if a worker is producing above the minimum, $i \notin L\left(\theta_{1}, g\right)$, his or her optimal level of effort would be given by $y_{i}^{*}=y\left(\theta_{i}, g\right)$. On the other hand, the effort of a worker producing at the minimum, $i \in L(\bar{y}, g)$, is given by $y_{i}^{*}=\bar{y}\left(\theta_{i}, g\right)$. It is clear that the lowest-ability worker will always be in the low-ability group (i.e., $1 \in L\left(\theta_{1}, g\right)$ ). There may be, however, more workers in this group. Depending on model parameters and $\mathrm{y}^{*}$, we have three cases:

1. If $y\left(\theta_{2}, g\right)>\bar{y}\left(\theta_{1}, g\right)$, worker $\theta_{2}$ would work more than the minimum in equilibrium because his or her effort without monetary motivation is already above the effort exerted by $\theta_{1}$. This must also be true for $\theta_{3}$ because $y\left(\theta_{3}, g\right)>y\left(\theta_{2}, g\right)$. Therefore, in equilibrium, $L\left(\theta_{1}, g\right)=\{1\}$, and hence $y_{1}^{*}<y_{2}^{*}<y_{3}^{*}$.

2. If $\underline{y}\left(\theta_{2}, g\right) \leq \bar{y}\left(\theta_{1}, g\right)<\underline{y}\left(\theta_{3}, g\right)$, worker $\theta_{2}$ 's optimal effort when he or she is above the minimum would be 
lower than $y_{1}^{*}$, which means that, in equilibrium, we must have $y_{1}^{*}=y_{2}^{*}$. Otherwise, worker $\theta_{2}$ can increase his or her payoff by decreasing effort. Therefore, in equilibrium, $L\left(\theta_{1}, g\right)=\{1,2\}$, and hence $y_{1}^{*}=y_{2}^{*}<y_{3}^{*}$.

3 . Finally, if $y\left(\theta_{3}, g\right) \leq \bar{y}\left(\theta_{1}, g\right)$, every worker produces the same in equilibrium, $L\left(\theta_{1}, g\right)=\{1,2,3\}$, and hence $y_{1}^{*}=y_{2}^{*}=y_{3}^{*}$. This case is equivalent to the standard case with only monetary motivation.

We now look at the manager's problem and analyze how he or she should set the team goal to maximize team production. To do so, we require an equilibrium refinement criterion. This is due to the possible multiplicity of equilibria in the low-ability group. Therefore, we make the assumption that when workers in the low-ability group face multiple equilibria, they choose an effort level corresponding with the payoff-dominant equilibrium $y_{i}^{*}=\bar{y}\left(\theta_{1}, g\right)$ for all $i \in L\left(\theta_{1}, g\right)$. This effort level corresponds to the highest effort the weak-link worker would willingly exert. The payoff dominance equilibrium refinement implies a unique pure strategy Nash equilibrium where

$$
y_{i}^{*}=\left\{\begin{array}{lll}
\bar{y}\left(\theta_{1}, g\right) & \text { if } & i \in L\left(\theta_{1}, g\right), \\
\underline{y}\left(\theta_{i}, g\right) & \text { if } & i \notin L\left(\theta_{1}, g\right) .
\end{array}\right.
$$

We note that determining whether the payoff dominance equilibrium refinement is a reasonable assumption becomes an empirical question. Classic weak-link coordination experiments with abstract effort rarely observe the payoff-dominant equilibrium (Van Huyck et al. 1990, Knez and Camerer 1994, Brandts et al. 2011). In fact, most of these experiments observe outcomes tending toward the least efficient equilibrium. However, recent coordination experiments (Vranceanu et al. 2015, Bortolotti et al. 2016) using real effort find the opposite: subjects' individual performance and coordination outcomes increase over time and approach the payoff-dominant equilibrium when one exists. As we show below, our results corroborate the findings from previous real effort coordination experiments, and we argue that the assumption of payoff dominance is reasonable in our setting. The intuition for Proposition 3 would be qualitatively similar under other equilibrium refinement assumptions such as the risk dominance in the low-ability group, where all workers choose $y\left(\theta_{1}, g\right)$, which corresponds with the least efficient equilibrium.

In the next proposition, we summarize important results on how the manager should set his or her goal. These results will help us build hypotheses for our experiment.

Proposition 3. For the payoff-dominant equilibrium,

(a) $\frac{d y_{i}^{*}}{d g}>0(<0)$ if and only if $y_{i}^{*}>g(<g)$, and

(b) The optimal goal set by the manager is given by $g^{*}=$ $\operatorname{argmax}_{g} \bar{y}\left(\theta_{1}, g\right)<y_{1}^{*}$.
Proposition 3(a) states that a worker's performance increases with the goal if his or her performance exceeds the goal (the goal is attainable), whereas the opposite is true if the worker's performance does not exceed the goal (the goal is unattainable). Therefore, increasing a goal that is too easy for a worker will be motivating, whereas increasing a goal that is too difficult for a worker will have a demotivating effect. Because the manager is concerned only about monetary payoffs from team production, which is unaffected by workers' performance above the minimum, a profitmaximizing manager focuses on maximizing the performance of the weak-link worker and hence will assign the maximum goal that he or she is willing and able to attain (Proposition 3(b)). Because this goal is met by the weak-link worker, it will also be attainable by higher-ability workers whose production is at or above $y_{1}^{*}=\bar{y}\left(\theta_{1}, g^{*}\right)$. Thus, in equilibrium, all workers of the team will attain the goal assigned by the manager.

We finish our theory section by discussing another implication of goals as reference points suggested by Heath et al. (1999) —namely, that difficult but attainable goals lead performance to "pile up" around the goal. Piling up follows directly from loss aversion (property 3 of the value function): loss aversion implies that a worker is substantially more motivated when just short of a goal than farther away from meeting the goal. In our environment, piling up indicates that the weak-link worker is just motivated enough to meet $g^{*}$, but if the goal were to be any higher, the weak-link worker's performance would decrease substantially, and the size of this reduction would be positively related to the loss aversion parameter $\lambda$. Note that this also implies that higher and lower goals than $g^{*}$ would yield a higher variation in performance. Thus, the optimal goal would have the lowest spread of work performance. In the next proposition, we show that wasted performance (performance above the weak-link level) is minimized at the optimal goal.

Proposition 4. Let us define $\Delta_{i}(g)=y\left(\theta_{i}, g\right)-\bar{y}\left(\theta_{1}, g\right)$ for $i \notin L\left(\theta_{1}, g\right)$; then $\Delta_{i}\left(g^{*}\right)<\Delta_{i}(g)$, for all $g \neq g^{*}$.

Proposition 4 is a direct implication of piling up. Goals that are higher than $g^{*}$ may boost high-ability workers' performance but decrease the weak-link worker's performance, generating not only a lower team production but also higher wasted performance. Similarly, goals that are lower than $g^{*}$ would decrease the performance of all workers on the team, but because of piling up, the decrease in the weak-link worker's performance will be more pronounced, leading again to lower team production and higher wasted performance.

To sum up, the optimal goal not only maximizes team production (Proposition 3) but also generates 
the lowest variation in performance among team members, minimizing wasted work performance (Proposition 4).

\section{Experimental Design}

We design our experiment to measure the impact of nonbinding goals on team outcomes. In Section 3.1, we discuss the real effort task in the experiment, commonly called the slider task. In Section 3.2, we detail the experimental design and timeline.

\subsection{Real Effort Task: Slider Task}

We employ the slider task introduced by Gill and Prowse (2012). The authors describe the task as consisting

of a single screen displaying a number of sliders.... When the screen containing the effort task is first displayed to the subject all of the sliders are positioned at $0 \ldots$ By using the mouse, the subject can position each slider at any integer location between 0 and 100 inclusive. Each slider can be adjusted and readjusted an unlimited number of times, and the current position of each slider is displayed to the right of the slider. The subject's "points score" in the task is the number of sliders positioned at 50 at the end of the allotted time. (Gill and Prowse 2012, p. 472)

We chose this real effort task for our experiment because of a number of desirable features, which are also noted in Gill and Prowse (2012). The task is easy to understand, requires no previous knowledge to complete, and is tedious to complete. Therefore, performance in the task is highly correlated with effort exerted.

\subsection{Experimental Procedure}

Subjects act as managers or workers on a team to complete the task at hand. Our experiment consists of two basic treatments, referred to as the baseline and the goal treatments. Treatments last for 13 rounds; in each round, subjects have two minutes to complete as many slider tasks as possible. In all treatments, subjects first attempt the real effort task for three individual rounds to become familiar with the task and establish a standard of ability. In these individual rounds, workers' payoffs are piece rate and determined by their individual performance. We use these initial rounds to compute subjects' ability levels.

In the baseline and goal treatments, players are randomly assigned to groups of four (one manager and three workers) and participate in the real effort weak-link coordination game. In each team round, workers complete the slider task for two minutes, after which the team production, the minimum performance among workers, is revealed to the group. Before the team rounds begin, the performance of each worker in the third individual round is revealed to the team. The manager has the option to complete the task as well, but his or her performance has no impact on team production, and it is never revealed to the workers. We allow managers to complete the task in case they want to remind themselves of how difficult the task may be. This is important because managers need information about the task difficulty to assign realistic goals. The payoff of all group members is determined by the minimum performance in each group. Therefore, every round, all subjects' monetary payoffs are identical within each group.

The only difference between the baseline and the goal-setting treatment is that managers can assign a nonbinding goal for team production in the goal treatment, whereas no such an option is available in the baseline. The groups in the baseline treatment still have a manager, although managers do not set goals for the team. Managers are subjects recruited from workers in a previous session where they get experience with the slider task.

We conducted all experimental sessions at the Laboratory for Economics, Management and Auctions (LEMA) at Pennsylvania State University between January 2015 and October 2017. We ran 24 matching groups of the baseline treatment and 24 matching groups of the goal treatment, although two groups of the goal treatment had to be dropped as a result of network connectivity issues. Therefore, we have 24 teams in the baseline treatment and 22 teams in the goal treatment, with a total of 184 subjects in our experiment. Our subject pool consisted of undergraduate students recruited through the automated online recruitment system. The experiment lasted for 1 hour, and subjects earned on average $\$ 14.78$ in the baseline treatment and $\$ 16.41$ in the goal treatment.

\subsection{Theoretical Predictions}

According to the theoretical analysis presented in Section 2, we have two different predictions for the individual effort depending on whether workers have a nonmonetary utility. If workers do not have a nonmonetary utility, the outcome of the coordination game would be consistent with Proposition 1, where effort is symmetric across all $n$ workers in equilibrium, and the weak-link worker $\theta_{1}$ sets the upper bound of equilibrium team production.

Hypothesis 1A. If workers only care about monetary payoffs, all workers' performance converges to a level that is a best response for the weak-link worker in both treatments.

Under the assumption that workers do not have a nonmonetary utility to complete the task, workers are only motivated by monetary incentives. Therefore, workers will not have incentives to perform above what is a best response for the weak-link worker, as 
shown in Proposition 1. However, if workers derive a nonmonetary utility from their individual performance that is independent of the team incentives, the prediction in both treatments could be given by the equilibria characterized in Proposition 2. When assigned goals are not present (in the baseline), the reference point is unobserved and idiosyncratic to each worker. Even though in both treatments workers may derive a nonmonetary utility from their own performance regardless of team incentives, the extensive goal-setting literature [see Locke and Latham (2002) for a review] indicates that assigned goals foster workers' motivation relative to a situation with no goals. Therefore, we can set the following hypothesis.

Hypothesis 1B. If workers derive a nonmonetary utility from their own performance,

(a) the average workers' performance should be higher than team production in both treatments, and

(b) the average workers' performance and team production should be higher in the goal treatment than in the baseline.

It also follows from our theory (Proposition 3(a)) that the goal that maximizes a worker's performance is the maximum goal that he or she is willing and able to achieve; consequently, profit-maximizing managers should assign goals that are challenging but achievable for the weak-link worker because the weaklink worker's performance determines team production and hence monetary payoffs (Proposition 3(b)).

Hypothesis 2. In the goal-setting treatment, we expect that

(a) Goals that are challenging but achievable maximize workers' performance, and

(b) Managers set goals that are challenging but achievable for the weak-link worker.

Finally, Proposition 4 indicates that the optimal goal minimizes wasted performance, the difference between the worker's performance and team production.

Hypothesis 3. In the goal-setting treatment, we expect that goals that are challenging but achievable for the weak-link worker minimize wasted performance in the team.

\section{Results}

We start the results section in Section 4.1 by looking at team production and an individual worker's performance in the baseline and goal treatments. We then proceed to look at goals set by the manager in Section 4.2 and study the effect of setting reasonably accurate goals for the weak-link worker, who determines team production. In Section 4.3, we study the selection of team goals by managers in more detail. Finally, in Section 4.4 , we analyze the effect of goal setting on the dispersion of performance among team members and wasted performance.
In the analysis of the results, we use workers' thirdround performance (last round of the individual production phase) as a measure of ability, which we call task ability. The average task ability for all workers is 13.97 in the baseline treatment and 13.12 in the goal treatment; although the average task ability is slightly higher in the baseline treatment, this difference is not statistically significant $(t=1.51, p=0.134)$. We define weak-link ability as the lowest ability in each group in round 3. Our results are qualitatively similar and statistically significant using several different measures for worker ability. These include second-round performance and the average or median of the early rounds' performance.

\subsection{Goal Setting, Team Production, and Worker Performance}

We begin by examining worker performance and team production in the baseline and goal treatments. Table 1 provides a summary of average worker performance and team production in the team rounds for both treatments, as well as the difference between treatments.

The average worker performance is consistently above the weak-link worker's performance in both treatments. The average effort of all workers in each group relative to team production is $112.4 \%$ in the goal treatment and $119.2 \%$ in the baseline treatment. This suggests that workers may derive intrinsic utility from the act of working, in line with Hypothesis 1B(a). Of course, there are alternative explanations for this result. For example, workers might work rather than do nothing as a result of lack of alternatives, a common problem in laboratory experiments known as the active participation hypothesis. Another possibility is that the desire not to be the weak-link worker drives up individual performance. These alternative explanations, however, do not explain why all workers perform better when assigned goals are present, which is a result consistent with Hypothesis $1 \mathrm{~B}(\mathrm{~b})$. When managers set goals for the team, team production is, on average, $19.8 \%$ higher than with the baseline treatment. This difference is statistically significant under both the Wilcoxon rank-sum $(p<0.01, z=-3.56)$ and Kolmogorov-Smirnov $(p<0.01)$ tests.

In Figure 1, we report team production and workers' performance over the 10 rounds in both

Table 1. Average Worker Performance and Team Production in Team Rounds

\begin{tabular}{lcc}
\hline Treatment & Worker Performance & Team Production \\
\hline Baseline & 12.48 & 10.47 \\
Goal & 14.1 & 12.55 \\
Difference (Goal - Baseline) & 1.62 & 2.08 \\
Difference (\%) & 13.0 & 19.8 \\
\hline
\end{tabular}


Figure 1. (Color online) Average Team Production and Workers' Performance in Both Treatments

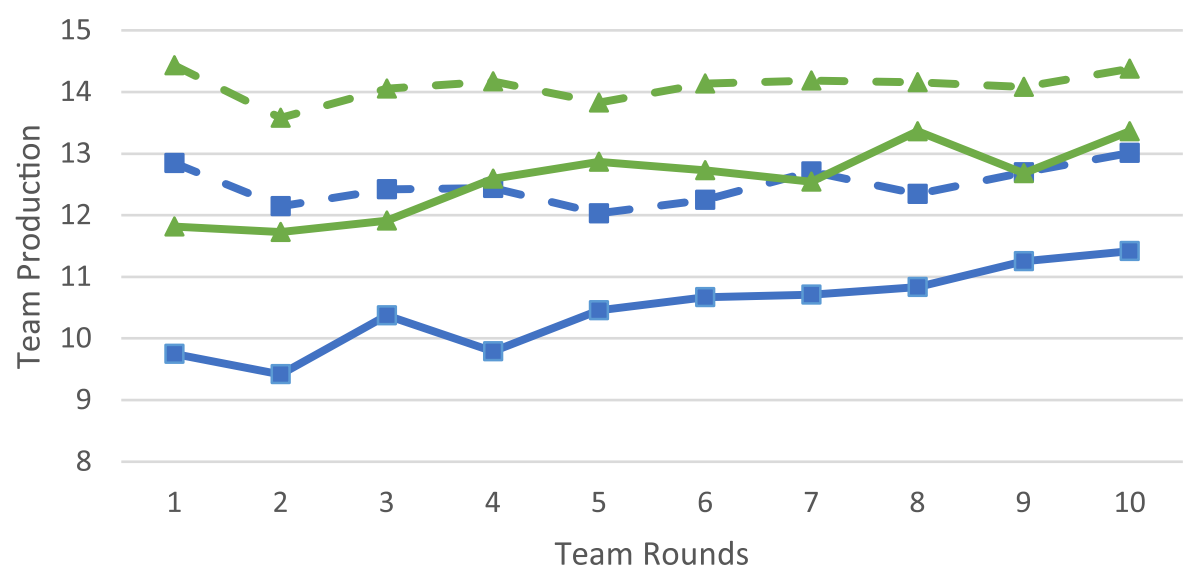

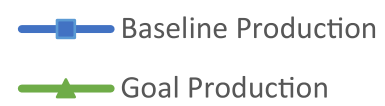

treatments. We see not only that are team production and worker performance above the minimum level of 0 but also that they increase over time in both treatments.

We present a paneled ordinary least squares (OLS) regression estimate of the effect of goal setting on team production at the group level in Table 2 . We find that team production is significantly higher in the goal treatment at the $0.1 \%$ level when controlling for weaklink ability. This implies that the difference in team production can be attributed to the goal treatment and not differences in individual workers between treatments. From these results, we conclude that goal setting has a significant positive effect on aggregate team production, which is consistent with Hypothesis $1 \mathrm{~B}(\mathrm{~b})$. We also see that the time trend is always statistically significant and positive for team production: team production is increasing over time for both treatments. Although this finding is unlike previous weak-link experiments with abstract effort, our result is in line with other real effort coordination experiments (Vranceanu

Table 2. Paneled OLS Regression on Team Production at the Group Level (Robust Standard Errors)

(1)

Variable

Team Production

Round

Goal Treatment ${ }^{\mathrm{a}}$

$0.185^{* * * *}$

(0.0453)

Weak-link Ability

$2.317^{* * * *}$

(0.475)

Weak-link Ability

$0.211^{* *}$

(0.104)

Constant

$6.514^{* * * *}$

(1.268)

Observations

\section{- Baseline Worker Performance \\ - $\triangle$ - Goal Worker Performance}

et al. 2015, Bortolotti et al. 2016). We take a closer look at what goals managers set in the next section.

Result 1 (Workers' Performance and Team Production). Workers' performance and team production are significantly greater in the goal treatment than in the baseline treatment, in line with Hypothesis 1B.

\subsection{Goal Accuracy for the Weak-Link Worker and Team Production}

We now study the effect of goal accuracy in the performance of the weak-link worker, which determines team production and hence monetary payoffs. The weak-link worker is fairly consistent within each group; $76 \%$ of the time, it is the same worker who determines team production. From our theory, we predict that setting the maximum goal the weak-link worker would attain in equilibrium maximizes his or her individual performance and hence team production (Hypothesis 2(a)). In Figure 2, we plot the average team production and average goal set by the manager. On initial inspection, managers appear to be setting goals that are too challenging for the weak-link worker; the average goal is 16.6, which is 4.1 units higher than the average team production. The average goal is so challenging that there are only 79 rounds out of the possible 220 where the team production meets or exceeds the goal. This result appears to be inconsistent with our theoretical conjectures.

One possible interpretation of this result is that managers set goals that are, on average, unattainable by weak-link workers because, in contrast to our theoretical framework, they find these goals to be most effective. To test the effectiveness of manager's goalsetting decisions, we need to identify reasonably accurate goals in the sense of being attainable yet

Note. Standard errors are in parentheses.

${ }^{\text {a } D u m m y ~ v a r i a b l e . ~}$

${ }^{* *} p<0.05 ; * * * p<0.001$. 
Figure 2. (Color online) Goals vs. Team Production

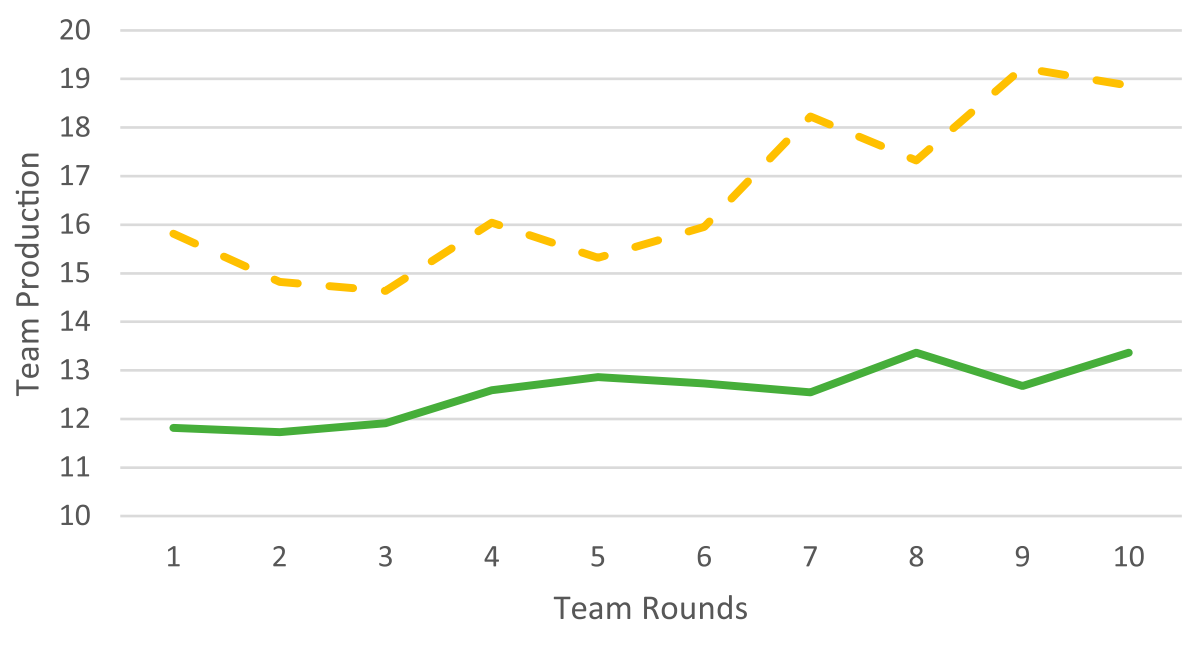

Average Production $\quad-$ Average Goal

challenging for the weak-link worker. Similar to Corgnet et al. (2015), we start by using the weak-link ability, the weak-link worker's output in round 3, to establish a basis for what goals are reasonable. However, in our team rounds with strategic complementarity, weak-link ability alone is not a good predictor of team production, and defining a goal as reasonable based on this predictor yields no insight. Therefore, using data from the baseline treatment, we estimate task ability in the current round as follows:

$$
\begin{aligned}
\text { Predicted task abilityt }= & \hat{\alpha}_{1} \times \text { lagged team production }+\hat{\alpha}_{2} \\
& \times \text { double lagged team production, }
\end{aligned}
$$

where $\hat{\alpha}_{1}$ and $\hat{\alpha}_{2}$ are estimated from the baseline treatment data with the following feasible generalized least squares linear panel regression with no constant:

$$
\begin{aligned}
\text { Team production }_{t}= & \alpha_{1} \times \text { lagged production }+\alpha_{2} \\
& \times \text { double lagged production }+\varepsilon_{t} .
\end{aligned}
$$

The linear panel feasible generalized least squares model allows us to suppress the constant while estimating the weighted coefficients of lagged dependent variables, unlike generalized method of moments $(\mathrm{GMM}) \mathrm{dy}-$ namic panels. We obtain $\hat{\alpha}_{1}=0.61$ and $\hat{\alpha}_{2}=0.39$, indicating that for the predicted task ability for a given round, $61 \%$ of the weight is placed on last round's team production and $39 \%$ of the weight is placed on team production from two rounds ago.

On the basis of the predicted task ability, we define the variable Reasonable Goal as a dummy that takes a value of 1 if the goal lies within a range of two units of predicted task ability, defined earlier as the weighted average of the team production from two previous rounds. We chose a range of 2 for our definition based on the standard deviation of team productions, which is 2.56 in the goal treatment and 2.68 in the baseline treatment. We observe reasonable goals for the weak-link worker in 117 of the 220 rounds, which is $53.2 \%$ of the rounds. Figure 3 shows the distribution of all goals minus predicted task ability (the red bars represent reasonable goals).

Next, we separate workers into two groups, weaklink workers and other (higher-ability) workers. As we indicated earlier, team production (i.e., performance of the weak link) is higher when goals are reasonable. In particular, weak-link workers on average complete 12.08 units when the goal is not reasonable and 13.0 units when the goal is reasonable for them. This difference is statistically significant as the session level under the Wilcoxon rank-sum test $(p=0.01)$. Conversely, the two other workers in the group complete 17.7 units when the goal is not reasonable for the weaklink worker and 17.9 units when the goal is reasonable for the weak-link worker. This difference is not statistically significant $(p=0.24)$. In Figure 4 , we report the aggregate effect of reasonable goals on team production. As noted in Section 4.1, team production is 2.08 units higher in the goal treatment compared with the baseline treatment, which is an increase of $19 \%$. When we look at reasonable goals compared with unreasonable goals, we see an even clearer picture: aggregate team production under reasonable goals is 13.0 , an increase of $24 \%$ compared with the baseline treatment. On the contrary, team production under unreasonable goals for the weak-link worker is 12.08 , which is only a $15 \%$ increase between the baseline and goal treatments. Therefore, we find empirical evidence that setting a reasonable goal for the weak-link worker is important to team success. Managers who set reasonable goals for the weak-link worker increase 
Figure 3. (Color online) Distribution of Goals-Predicted Task Ability (Reasonable Goals in Red)

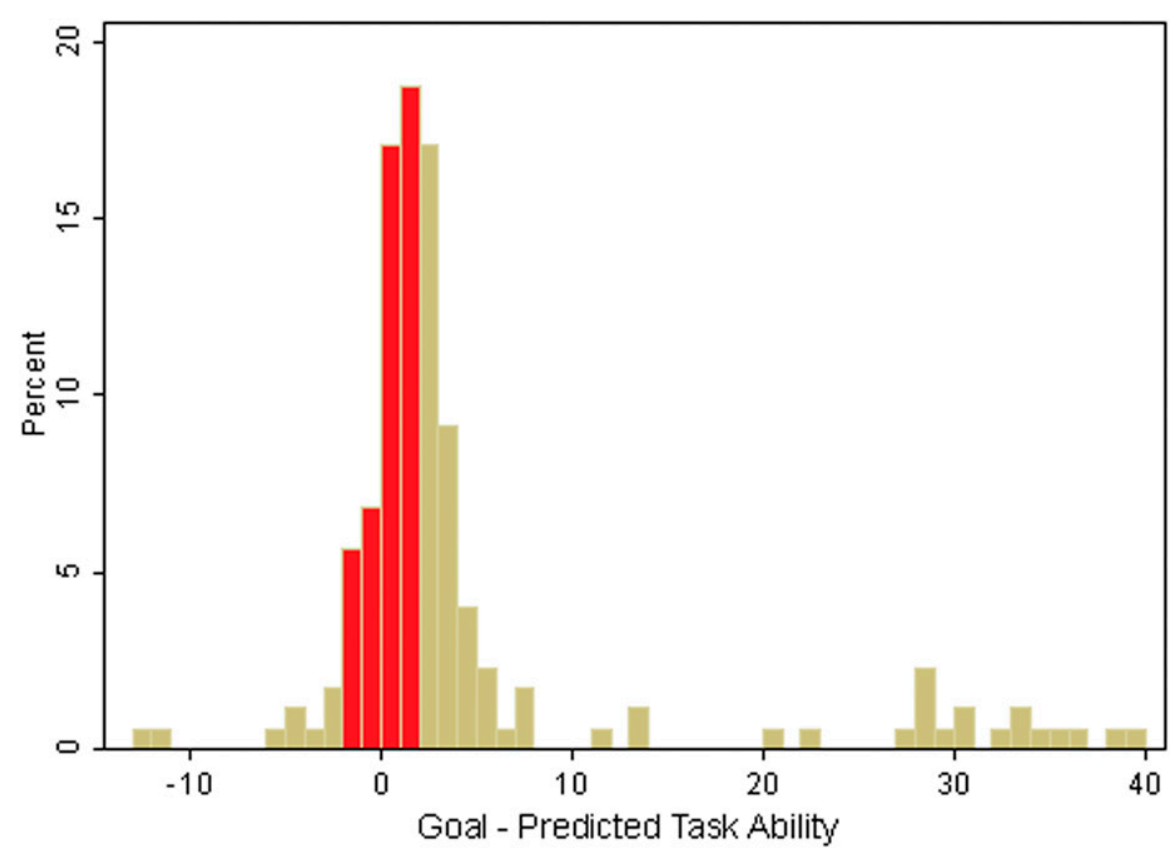

monetary payoffs for their teams by almost $25 \%$, whereas managers who set unreasonable goals observe much smaller gains to team production.

Although setting reasonable goals for the weaklink worker theoretically (Hypothesis 2(b)) and empirically increases team production, we still find that almost half the managers in our sample seem to assign goals according to different criteria, which prevents them from fully capitalizing on the monetary gains of goal-setting policies. We study the manager's goal selection in more detail in the next section, where we propose a possible interpretation of these results.

Result 2 (Goal Accuracy and Team Production). Managers set reasonable goals for the weak-link worker in $53.2 \%$ of the rounds, so empirical support for Hypothesis 2(b) is ambiguous. Reasonable goals improve aggregate team production by $24 \%$ compared with the baseline treatment. Unreasonable goals have a smaller effect. This is clear empirical support for Hypothesis 2(a).

\subsection{Managers' Goal Selection}

We saw in the preceding section that some managers in our experiment are not setting the goals that maximize team production. Of the 103 observations of unreasonable goals, 87 are goals that are above actual team production; 23 of these goals are at least 10 units above actual team production. These managers may believe that setting increasingly difficult and

Figure 4. (Color online) Reasonable vs. Unreasonable Goals for the Weak-Link Worker and Team Production

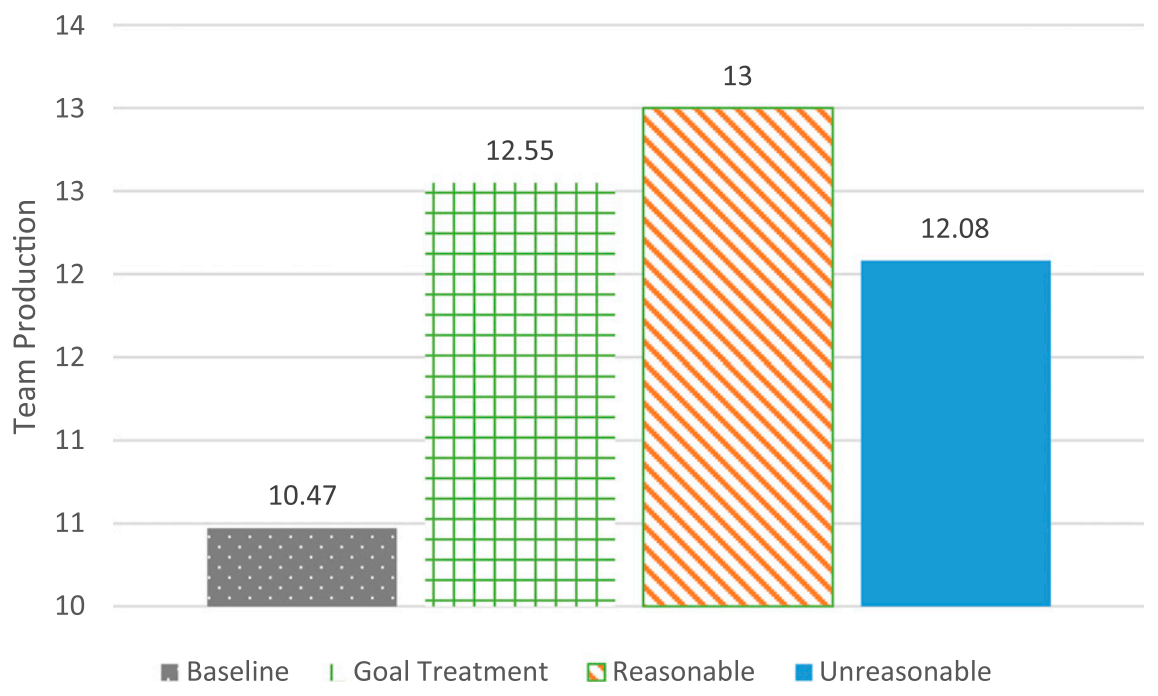


unattainable goals will motivate the weak-link worker to improve performance, contrary to our theory and empirical evidence, or they may be setting goals for reasons different from profit maximization. In Table 3, we present two linear dynamic panel-data models on goals at the group level when they are unreasonable and when they are reasonable (we use the ArellanoBover/Blundell-Bond generalized method of moments system estimator to avoid endogeneity bias that may arise in paneled OLS estimations with lagged dependent and independent variables). In particular, reasonable goals are correlated with team production in the previous round, whereas unreasonable goals are not. The result suggests that managers who set reasonable goals for the weak link update goals based on feedback from previous team production. However, managers assigning unreasonable goals do not seem to consider team production at all. In other words, only managers who set reasonable goals seem to focus on the weak link's previous performance, which our theory and empirical evidence suggest is the optimal way of assigning goals.

We also see that the time trend is marginally statistically significant and positive for unreasonable goals, indicating that these managers are setting increasingly difficult goals over time, even though most team productions are far below these goals. If all managers were learning to set more motivating goals over time, we would see the difference between goals and team productions shrinking over time. Instead, unreasonable goals become increasingly difficult and unrealistic compared with team production. Finally, we look at the correlation between goals and the ability of the most productive worker, which we call High Task Ability. This variable measures the third-

Table 3. GMM Linear Dynamic Panel Data Model on Goals at the Group Level

\begin{tabular}{lcc}
\hline & $(1)$ & $(2)$ \\
Variable & Unreasonable Goal & Reasonable Goal \\
\hline Lagged Goal & 0.224 & 0.0185 \\
& $(0.222)$ & $(0.0663)$ \\
Lagged Production & -0.116 & $0.319^{* * *}$ \\
& $(0.349)$ & $(0.0921)$ \\
Weak-link Ability & -1.103 & 0.273 \\
& $(2.080)$ & $(0.450)$ \\
High Task Ability & $1.776^{*}$ & 0.0637 \\
& $(0.859)$ & $(0.223)$ \\
Manager Ability & 1.495 & 0.186 \\
& $(0.923)$ & $(0.120)$ \\
Round & $1.738^{*}$ & -0.0826 \\
& $(0.784)$ & $(0.0979)$ \\
Constant & -35.78 & 3.814 \\
& $(30.20)$ & $(2.334)$ \\
Observations & 81 & 117 \\
\hline
\end{tabular}

Note. Standard errors are in parentheses. ${ }^{*} p<0.10 ;{ }^{* *} p<0.01$. round performance of the most productive worker on the team, similar to weak-link ability. For goals that are unreasonable, the most productive worker's ability is marginally correlated with the goal, whereas team production is not. This evidence suggests that some managers are setting goals that are appropriate for the best workers of the team, but these goals are too difficult for the weak link. This failure to adapt goal-setting strategy in a team production environment lowers profits for all team members. In Table A.1 in the appendix, we consider an alternative model specification where we categorize managers as reasonable managers if they set seven or more reasonable goals out of the 10 team rounds. Similar to the results in Table 3, we observe that reasonable managers set goals correlated with team production in the previous round, whereas unreasonable managers do not. Unreasonable managers set goals correlated with high task ability.

Our results are in line with other economic, psychology, and management science studies, which find that some managers are reluctant to adapt their strategies to feedback on workers' characteristics. For example, using data from a company that provide online job testing services, Hoffman et al. (2018) study the effects of job testing on managerial hiring decisions and performance. The authors found that human resource managers who frequently use their discretion to override the results of a proprietary skills test hired workers who performed worse than workers hired by other managers. Similarly, in a laboratory experiment, Corgnet and Hernán González (2014) report evidence that consulting workers was beneficial to managers as long as they follow the workers' advice; nevertheless, most managers were reluctant to change their mind and adopt the workers' proposal. Thus, most managers ignore proposals in favor of their original plan despite the monetary costs. This rigidity of mind may arise because people focus too much on their own beliefs instead of adapting their strategies to somebody else's feedback. In other words, managers may suffer from the well-documented self-serving bias (Loewenstein et al. 1993, Babcock et al. 1996, Babcock and Loewenstein 1997). In line with this idea, some managers in our experiment may believe that all workers should achieve the performance dictated by the highestability workers without paying proper attention to the negative motivational effects of setting too challenging goals for weak-link workers. When these workers fail to reach the goal, some managers ignore this feedback and do not adjust their strategy even when it is in their material interest to do so. The observation that some managers misunderstand or ignore feedback is common in the operations and management literature as well. For example, Sterman (1989) finds that human subjects experience several "misperceptions 
of feedback" in a multitier inventory distribution system with time delay, commonly known as the beer game. The misperceptions of feedback result in the bullwhip effect, and Chen et al. (2000) demonstrate that the behavioral phenomenon does not disappear even with centralized demand information.

Result 3 (Managerial Goal Selection). Although $53.2 \%$ of the time managers set reasonable goals, some managers persistently set unreasonable goals that increase in difficulty over time. This finding is contrary to Hypothesis 2(b) and suggests that some managers have alternative strategies on how to set goals—strategies that are suboptimal from the point of view of profit maximization.

\subsection{Dispersion of Workers Performance and Wasted Performance}

Finally, we look at the dispersion of workers' performance within each treatment. Table 4 summarizes the mean and standard deviation of all workers' performance, as well as the mean and standard deviation of weak-link workers' performance versus other workers, and the test of equality of standard deviations statistics between the baseline and goal treatments, both at the session level. We see that there is greater dispersion of performance when goals are present. This empirically suggests that, on average, goals set by managers act as a motivation device rather than a coordination device. Thus, goals increase all workers performance, but they also disperse individual worker performance.

To understand why goals increase the standard deviation of workers performance, we introduce the variable Wasted Performance, which we define as a worker's performance above the weak-link worker's level. As we explained in Section 4.1, we chose the label wasted because performance levels above the minimum do not result in monetary earnings. Our theory suggests that because of piling up, wasted performance is minimized when goals are challenging but attainable for the weak-link worker. Table 5 presents results from a Z-test of equality of means, clustered by session, for wasted performance from the other two higher-ability workers, because, by definition, the weak-link worker wasted performance is 0 . We note that there is no statistical difference in wasted performance between the baseline and goal treatments. However, when we analyze wasted performance in the goal treatment and separate observations by when there is an unreasonable versus reasonable goal, we find that wasted performance is significantly higher at the session level when workers face an unreasonable goal. This finding is consistent with Hypothesis 3: reasonable goals that are challenging but attainable for the weak-link worker minimize wasted performance and hence decrease the standard deviation of performance.

Result 4 (Wasted Performance). The standard deviation of workers' performance is higher when goals are present. We show that this is because unreasonable goals significantly increase wasted performance. However, reasonable goals significantly decrease wasted performance and hence the spread of performance among workers in the team. These results are consistent with Hypothesis 3.

\section{Discussion}

In this study, we test the efficacy of nonbinding goals in teams where production depends on the weak-link worker. To do so, we model team production as a real effort weak-link coordination game among workers, where managers can set a goal for the team. We find that nonbinding goals are effective motivators for teams in our experiment. In particular, aggregate team production increases by $19.8 \%$ when goals are present, and this positive effect is more pronounced when the goal is reasonable for the weak-link worker. The positive effect of goals on teams' production holds even when controlling for measures of workers' individual ability within groups. We also find that in the absence of goals, team production does not fall to the worst possible outcome of zero. This finding differs from the large body of literature on abstract effort minimum coordination games, where convergence to the least efficient equilibrium is the norm, but is consistent with other real effort experiments.

Table 4. Test of Equality of Standard Deviations for Workers' Performance at the Group Level

\begin{tabular}{lcrccc}
\hline Workers & Treatment & $N$ & Mean & Std. dev. & $F$-test \\
\hline All workers & Baseline & 122 & 13.27 & 3.05 & $p=0.02$ \\
& Goal & 114 & 15.02 & 3.72 & Reject \\
Weak-link workers (Team outcome) & Baseline & 54 & 11.06 & 2.00 & $p=0.11$ \\
& Goal & 52 & 12.57 & 2.39 & Fail to reject \\
Other workers & Baseline & 68 & 15.55 & 2.57 & $p=0.01$ \\
& Goal & 62 & 17.74 & 3.39 & Reject \\
\hline
\end{tabular}


Table 5. Z-Test of Equality of Means for Wasted Performance at the Group Level

\begin{tabular}{lcccc}
\hline Treatment & $N$ & Clusters & Mean & $t$-Test \\
\hline Baseline & 456 & 24 & 5.19 & $p=0.57$ \\
Goal & 416 & 22 & 5.26 & Fail to reject \\
Unreasonable goal & 198 & 22 & 5.46 & $p=0.03$ \\
Reasonable goal & 218 & 21 & 5.09 & Reject \\
\hline
\end{tabular}

Our paper shows that workers on teams respond to nonmonetary incentives such as goal setting. Using nonbinding managerial goals in organizations is particularly appealing because these goals are easy and costless to implement. Furthermore, these goals can significantly increase team production while also avoiding conflicts of interest between management and workers. When a goal is binding, the firm or manager must pay the monetary incentive when the goal is met; this can lead the firm or manager to set goals that do not maximize team production. Nonbinding goals can align the incentives of both parties.

Our results also indicate that not all goals are equally effective. In particular, we find that setting unrealistic team goals (goals that are too difficult for the weak-link worker) is much less effective than setting reasonable goals. Unfortunately, almost half of the time, our managers set goals that are too difficult, and this effect is persistent. We argue that this important result is consistent with similar findings in the literature on selfserving biases. Our results suggest that it would be beneficial to train managers to overcome their rigidity of mind when setting goals for others. Through training, organizations can teach managers to overcome personal idiosyncrasies and assign better goals for their teams. When managers are able to empathize with their weak-link workers and use available information to set challenging yet achievable goals for them, teams as well as managers benefit. Moreover, our finding that suboptimal goals also increase wasted performance suggests that improving goal-setting strategies is especially important in production settings where overperformance is costly for the firm (scrap, energy use, inventory costs, lower prices as a result of oversupply, etc.).

Our findings suggest several interesting lines for future research. First, the result that some managers are unsuccessful at setting optimal goals even when the necessary information is at their disposal motivates the question of how to minimize the impact of managerial mistakes or biases in setting team goals. Firms may adopt policies to improve managers' goalsetting behavior, such as increasing feedback about goals that are challenging but attainable for the weak link. Moreover, it would be interesting to delve more into the role that managerial leadership has on goal effectiveness in teams. In our experiment, we focus on a vertical leadership environment in which managers are always in charge of goal setting; however, one might imagine that workers might be more committed to attain team goals when they participate in setting them (horizontal leadership) or when the manager simply asks for the workers' opinion before assigning the goals (consultative leadership). Different leadership structures may moderate the impact of nonbinding goals and intrinsic motivation on worker performance and team production. From a theoretical standpoint, our model could be generalized to consider randomness in workers' production, which would lead to a more complex probability distribution over outcomes and hence additional coordination problems. Finally, it is worth exploring the impact of binding goals on teams with diverse production technologies. Binding goals such as sales quotas and project deadlines directly affect a worker's monetary incentives, and these goals are commonplace as well. Whether managers set optimal binding goals and what impact these goals have on team production remain important open questions.

\section{Acknowledgments}

The authors thank department editor Brian Tomlin, the associate editor, and the anonymous referees for their insightful feedback on the theory and experimental design throughout the review process. They also thank Anthony Kwasnica for thoughtful advice on all aspects of the paper, and they thank LEMA at Pennsylvania State University for partial funding and use of the facilities.

\section{Appendix. Proofs}

\section{Proof of Proposition 1}

First, we show that $y_{i}=y_{-i}$ with $0 \leq y_{i} \leq \tilde{y}$ is a Nash equilibrium. Suppose that $y_{i}=y^{*}$ for all $i$ and $0 \leq y \leq \tilde{y}$. Now suppose that worker $i$ chooses $y_{i}>y$. Worker $i$ 's payoff is given by $\pi_{i}^{w}\left(y_{i}, y_{-i}\right)=A \cdot M(\mathbf{y})-c\left(y_{i} ; \theta_{i}\right)<A \cdot M(\mathbf{y})-c\left(y ; \theta_{i}\right)=$ $\pi_{i}^{w}\left(y^{*}\right)$. This is because $c(\cdot)$ is increasing in $y$ for all workers. Therefore, worker $i$ has no incentive to increase effort above $y^{*}$.

Now consider any $y_{i}<y$. In other words, worker $i$ unilaterally sets the minimum. By assumption, $0 \leq y \leq \tilde{y}$, and in this range $\pi^{w}\left(y_{i}, y_{-i}\right)<\pi^{w}\left(y, y_{-i}\right)$. This is to say, in this range, the monetary payoff from a higher team production level outweighs the increased cost of effort for all workers. Therefore, a worker has no incentive to decrease effort.

Now we show that any Nash equilibrium to this game satisfies $y_{i}=y_{-i}$ with $0 \leq y_{i} \leq \tilde{y}$. Suppose that $y^{*}$ is a pure strategy Nash equilibrium. First assume that $y^{*}$ is not a constant vector. Then there exists $y_{i}>M(y)$ for some $i$, so worker $i$ can increase profits by setting $y_{i}=M(y)$. Doing so will decrease his or her cost of effort without decreasing his or her monetary payoffs. Now assume that $y^{*}>\tilde{y}$. For any worker with ability parameter $\theta_{1}$, his or her profit function is decreasing in this range. He or she can increase profits by choosing $y_{i}<y^{*}$.

\section{Proof of Proposition 2}

Following Wu et al. (2008), we consider a special case of optimization referred to as myopic optimization. We require 
this assumption because solutions of the optimization problem with a prospect theory value function are not necessarily unique.

Assumption A.1 (Myopic Optimization). The worker stops performing when the marginal cost of obtaining an additional unit first exceeds the marginal benefit of obtaining that unit. Thus, the optimal performance is given by $y^{*}=\min \left\{y_{1}, \ldots, y_{n}\right\}$, where $y_{1}, \ldots, y_{n}$ are solutions to $v^{\prime}(y-g)=c_{y}(y ; \theta)$.

In essence, Assumption A.1 guarantees that the solution will be the minimum performance of all possible equilibria. Thus, without this assumption, the optimal work performance that we compute below could be higher, but none of our qualitative results, in particular the relationship between work performance and goal setting, would change.

To prove Proposition 2, we established the following lemma.

Lemma A.1. Let Assumption A.1 hold. Then $v^{\prime \prime}\left(y^{*}-g\right)<$ $c_{y y}\left(y^{*} ; \theta\right)$.

Proof of Lemma 1. Because $y^{*}$ is the profit-maximizing performance given goal $g, v^{\prime}\left(y^{*}-g\right)=c_{y}\left(y^{*} ; \theta\right)$. Because $v(\cdot)$ is concave for gains and $c(\cdot)$ is convex, Assumption A.1 implies $v^{\prime}\left(y^{*}-g-\varepsilon\right)>c_{y}\left(y^{*}-\varepsilon ; \theta\right)$. Therefore, $v^{\prime \prime}\left(y^{*}-g\right)<c_{y y}\left(y^{*} ; \theta\right)$.

Note that Lemma A.1 ensures that second-order condition for the performance that maximizes worker's overall utility $\pi^{w}(\cdot)=A \cdot M(\mathbf{y})+v\left(y_{i}-g\right)-c\left(y_{i} ; \theta_{i}\right)$ holds.

Let us consider $\theta \in\left[\theta_{1}, \theta_{n}\right]$. A worker with ability $\theta$ producing above the minimum is not affected by monetary incentives, and his or her best-response effort choice is characterized by

$$
\underline{y}(\theta, g)=\left\{y: v^{\prime}(y-g)=c_{y}(y ; \theta)\right\}
$$

Alternatively, a worker producing at the minimum is affected by monetary incentives, and his or her best-response effort choice is given by

$$
\bar{y}(\theta, g)=\left\{y: A+v^{\prime}(y-g)=c_{y}(y ; \theta)\right\} .
$$

Note that for $A>0, y(\theta, g)<\bar{y}(\theta, g)$ for all workers. We first prove that both $\bar{y}(\cdot)$ and $y(\cdot)$ increase in $\theta$ for a given $g$. Note that by differentiating $\overline{\bar{y}}(\theta, g)$ or $y(\theta, g)$ with respect to $\theta$ and using the implicit function theorem, we get

$$
v^{\prime \prime}(y-g) \frac{d y}{d \theta}=c_{y y}(y ; \theta) \frac{d y}{d \theta}+c_{y \theta}(y ; \theta),
$$

where $y$ stands for either $\bar{y}(\cdot)$ or $\underline{y}(\cdot)$. By rearranging terms, we get

$$
\frac{d y}{d \theta}=\frac{c_{y \theta}(y ; \theta)}{v^{\prime \prime}(y-g)-c_{y y}(y ; \theta)} .
$$

The denominator of this expression is negative because of Lemma A.1, whereas the numerator is negative by the properties of $c(\cdot)$. Hence, $\frac{d y}{d \theta}>0$, and both $\bar{y}(\cdot)$ and $\underline{y}(\cdot)$ increase in $\theta$ for a given $g$.

Now, for a given $g \geq 0$, let us define the threshold ability level $\tilde{\theta}\left(\theta_{1}\right)$ as $y\left(\tilde{\theta}\left(\theta_{1}\right), g\right)=\bar{y}\left(\theta_{1}, g\right)$. Note that because both $\underline{y}(\cdot)$ and $\bar{y}(\cdot)^{-}$increase in $\theta, \theta \geq \tilde{\theta}\left(\theta_{1}\right)$ if and only if $\bar{y}\left(\theta_{1}, \bar{g}\right) \leq \underline{y}(\theta, g)$. Therefore, we can define the low-ability workers group as $L\left(\theta_{1}, g\right)=\left\{i \in N \mid y\left(\theta_{i}, g\right) \leq \bar{y}\left(\theta_{1}, g\right)\right\}$, which has cardinality of at least 1 ; thus, $\bar{\theta}_{1}$ will always be in this group. If $\left|L\left(\theta_{1}, g\right)\right|=1$, worker $\theta_{1}$ is the only low-ability worker, and his or her best-response effort level is the solution to $A+v^{\prime}(y-g)=c_{y}\left(y ; \theta_{1}\right)$. This is a unique pure strategy Nash equilibrium.

If $\left|L\left(\theta_{1}, g\right)\right| \geq 2$ then, applying the logic of Proposition 1 , we see that for all $i \in L\left(\theta_{1}, g\right), y_{i}=y^{*}$, where $y\left(\theta_{1}, g\right) \leq y^{*} \leq \bar{y}\left(\theta_{1}, g\right)$. Finally, for all $i \notin L\left(\theta_{1}, g\right)$, it holds that $y\left(\theta_{i}, g\right)>\bar{y}\left(\theta_{1}, g\right)$. Hence, in equilibrium, these workers' best-response effort levels are not affected by monetary team incentives, and $y_{i}=\bar{y}\left(\theta_{i}, g\right)=\left\{y: v^{\prime}(y-g)=c_{y}\left(y ; \theta_{i}\right)\right\}$ is a pure strategy Nash equilibrium.

\section{Proof of Proposition 3}

To prove Proposition 3, we assume a widely accepted equilibrium refinement criterion that states that when workers in the low-ability group face multiple equilibria in the coordination game, they choose an effort level corresponding to the payoff-dominant equilibrium.

Assumption A.2 (Payoff Dominance). Low-ability workers with ability parameters $\theta_{1}, \ldots, \theta_{m}$ choose the symmetric bestresponse effort level that yields the payoff-dominant equilibrium in the coordination game. In our context, the effort level is the solution to $A+v^{\prime}(y-g)=c_{y}\left(y ; \theta_{1}\right)$. This effort level is the maximum effort the weak-link worker would willingly exert.

Given Assumption A.2, there is a unique pure strategy Nash equilibrium in this game, where low-ability workers exert effort $y_{i}=\bar{y}\left(\theta_{1}, g\right)=\left\{y: A+v^{\prime}(y-g)=c_{y}\left(y ; \theta_{1}\right)\right\}$ and high-ability workers exert effort $y_{i}=y\left(\theta_{i}, g\right)=\left\{y: v^{\prime}(y-g)=\right.$ $\left.c_{y}\left(y ; \theta_{i}\right)\right\}$.

The proof of Proposition 3(a) is based on the Wu et al. (2008) analysis of a goal-dependent prospect theory value function with exogenously given goals. This result is similar to proposition 1 in $\mathrm{Wu}$ et al. (2008).

Given Proposition 2 and Assumption A.2, the optimal production is given by

$$
y_{i}^{*}=\left\{\begin{array}{lll}
\bar{y}\left(\theta_{1}, g\right) & \text { if } & i \in L(\bar{y}, g), \\
\underline{y}\left(\theta_{i}, g\right) & \text { if } & i \notin L(\bar{y}, g) .
\end{array}\right.
$$

Let us start by showing how goals affect the effort of workers in the high-ability group $\left(i \notin L\left(\theta_{1}, g\right)\right)$. Given a goal, the optimal performance for high-ability workers is characterized by Equation (A.1):

$$
v^{\prime}(\underline{y}(\theta, g)-g)=c_{y}(\underline{y}(\theta, g) ; \theta) \text {. }
$$

Using the implicit function theorem and differentiating both sides with respect to $g$, we get

$$
\begin{aligned}
& v^{\prime \prime} \underline{(\underline{y}(\theta, g)-g)\left(\frac{d y(\theta, g)}{d g}-1\right)}=c_{y y}(\underline{y}(\theta, g) ; \theta) \frac{d \underline{y}(\theta, g)}{d g} \\
& \Rightarrow \frac{d \underline{y}(\theta, g)}{d g}=\frac{v^{\prime \prime}(\underline{y}(\theta, g)-g)}{v^{\prime \prime}(\underline{y}(\theta, g)-g)-c_{y y}(\underline{y}(\theta, g) ; \theta)} .
\end{aligned}
$$

The denominator of this expression must be negative at the optimal performance level because it is the second-order condition for an effort level that maximizes a worker's overall utility. Therefore, $\frac{d y(\theta, g)}{d g}$ and $v^{\prime \prime}(\underline{y}(\theta, g)-g)$ must have 
Figure A.1. (Color online) Plot of $\hat{g}$ and $\hat{y}$

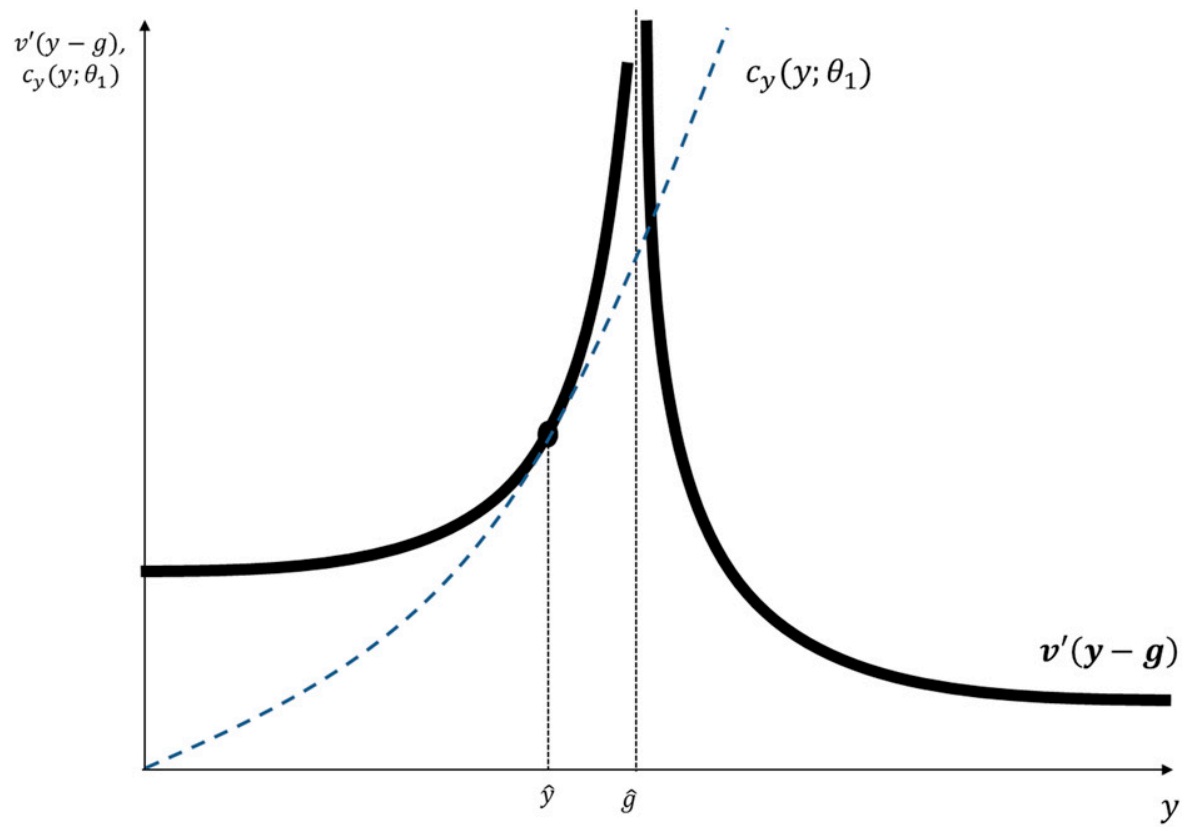

opposite signs. Moreover, note that by properties 4 and 5 of $v(y-g)$, we know that $v^{\prime \prime}(y(\theta, g)-g)>0(<0)$ if and only if $y(\theta, g)<g(>g)$. This means that higher goals improve the performance of a high-ability worker, if his or her performance exceeds the goals (the goal is attainable for him or her) but decreases performance if his or her performance does not exceed the goal (the goal is not attainable for him or her). Thus, $\frac{d y(\theta, g)}{d g}>0(<0)$ if and only if $y(\theta, g)>g(<g)$.

Similarly, given a goal, the optimal performance for workers in the low-ability group $\left(i \in L\left(\theta_{1}, g\right)\right)$ is given by Equation (A.2):

$$
A+v^{\prime}\left(\bar{y}\left(\theta_{1}, g\right)-g\right)-c_{y}\left(\bar{y}\left(\theta_{1}, g\right) ; \theta_{1}\right) .
$$

Figure A.2. (Color online) Plot of $g^{*}$ and $\bar{y}\left(\theta_{1}, g^{*}\right)$
By deriving both sides of this expression with respect to $g$, we get

$$
\begin{gathered}
v^{\prime \prime}\left(\bar{y}\left(\theta_{1}, g\right)-g\right)\left(\frac{d \bar{y}\left(\theta_{1}, g\right)}{d g}-1\right)=c_{y y}\left(\bar{y}\left(\theta_{1}, g\right) ; \theta\right) \frac{d \bar{y}\left(\theta_{1}, g\right)}{d g} \\
\Rightarrow \frac{d \bar{y}\left(\theta_{1}, g\right)}{d g}=\frac{v^{\prime \prime}\left(\bar{y}\left(\theta_{1}, g\right)-g\right)}{v^{\prime \prime}\left(\bar{y}\left(\theta_{1}, g\right)-g\right)-c_{y y}\left(\bar{y}\left(\theta_{1}, g\right) ; \theta_{1}\right)} .
\end{gathered}
$$

Using the same argument, $\frac{d \bar{y}\left(\theta_{1}, g\right)}{d g}>0(<0)$ if and only if $\bar{y}\left(\theta_{1}, g\right)>g(<g)$.

We now proceed to prove Proposition 3(b). Note that a profit-maximizing manager should focus on maximizing the performance of the weak-link worker, the only one determining the team's production. In Proposition 3(a), we showed that

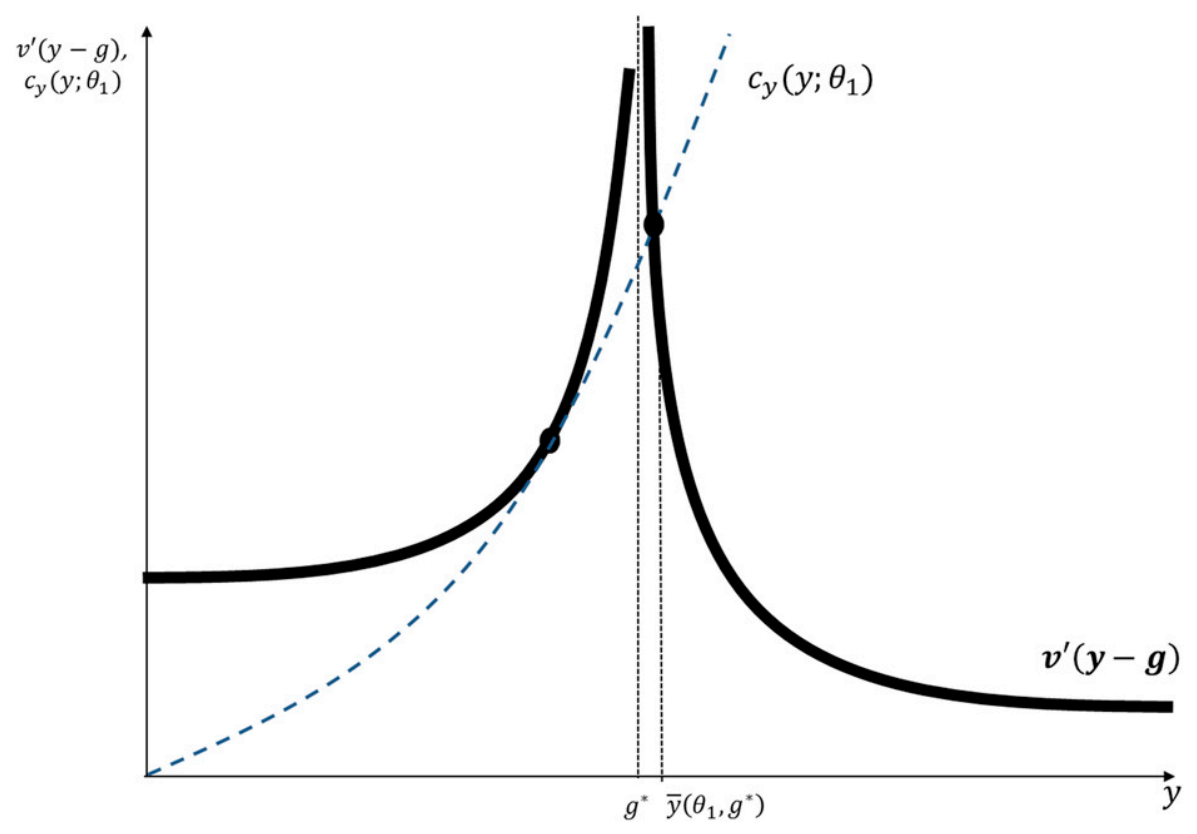


Figure A.3. (Color online) Wasted Performance of the Highest-Ability Worker Under the Optimal Goal (Left-Hand Side) and a Higher Goal (Right-Hand Side)

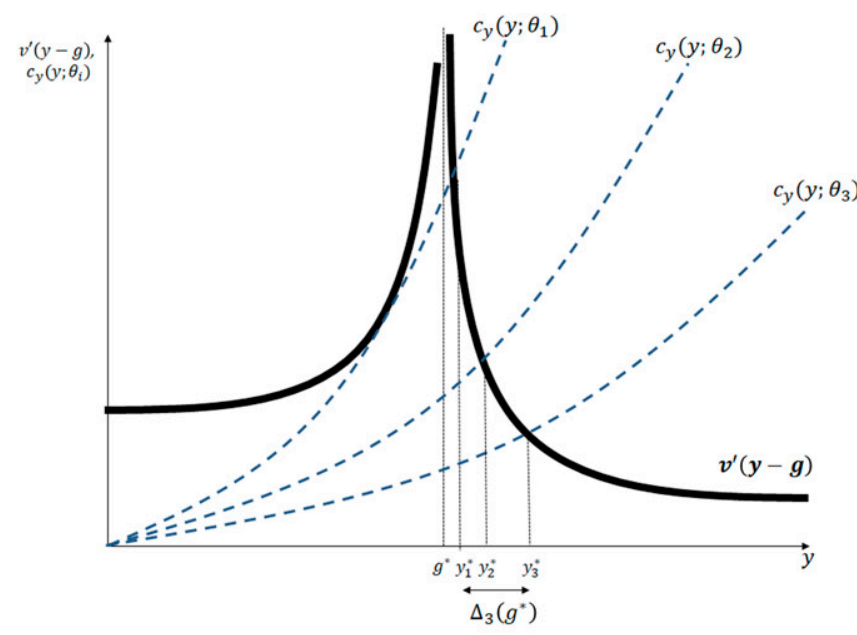

this goal corresponds to the maximum goal that the weak-link worker is willing and able to attain (i.e., $g^{*}=\operatorname{argmax}_{g} \bar{y}\left(\theta_{1}, g\right)$ ).

To compute $g^{*}$, we start by defining $\hat{g}$ as the minimum goal that the weak-link worker would fail to attain and $\hat{y}$ as its corresponding performance (see Figure A.1).

From Equation (A.2), we know that

$$
A+v^{\prime}(\hat{y}-\hat{g})=c_{y}\left(\hat{y} ; \theta_{1}\right) \text {. }
$$

By deriving both sides of this equation with respect to $\hat{y}$, we get

$$
v^{\prime \prime}(\hat{y}-\hat{g})=c_{y y}\left(\hat{y} ; \theta_{1}\right)
$$

We can compute $\hat{g}$ and $\hat{y}$ by solving the following system of equations:

$$
\begin{aligned}
v^{\prime \prime}(\hat{y}-\hat{g}) & =c_{y y}\left(\hat{y} ; \theta_{1}\right), \\
v^{\prime}(\hat{y}-\hat{g}) & =c_{y}\left(\hat{y} ; \theta_{1}\right) .
\end{aligned}
$$

Finally, note that because $\hat{g}$ is the minimum goal that the weak-link worker would fail to attain, the maximum goal

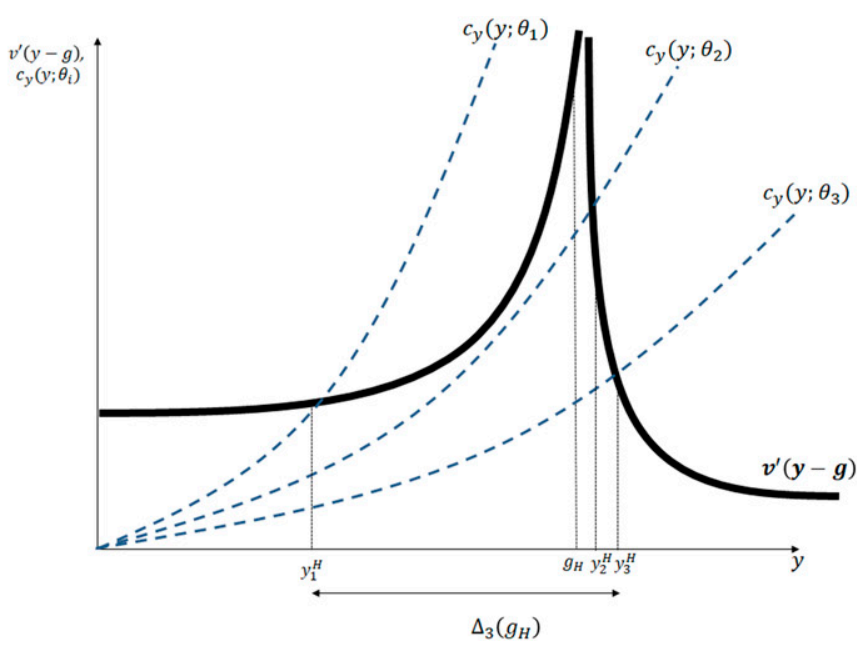

that he or she could attain is slightly lower. Thus, $g^{*}=\hat{g}-\varepsilon$ with $\varepsilon \rightarrow 0$, as shown in Figure A.2.

\section{Proof of Proposition 4}

This proof is based on the proof of proposition 5 in $\mathrm{Wu}$ et al. (2008). First, we formalize the notion of piling up. Let us call $G(\delta ; \theta, \lambda)$ the set of goals in which performance exceeds a particular goal by $\delta$ or less. Thus, if $g \in G(\delta ; \theta, \lambda)$, then $0 \leq y_{i}-g \leq \delta$.

To check how piling up is related to loss aversion in our environment, we prove the following lemma.

Lemma A.2 (Piling Up). There exists a sufficiently high level of loss aversion $\lambda>1$ such that if $g \in G\left(\delta ; \theta_{i}, 1\right)$, then $g \in$ $G\left(\delta ; \theta_{1}, \lambda\right)$, where $i \notin L\left(\theta_{1}, g\right)$.

Proof of Lemma A.2. If $g \in G\left(\delta ; \theta_{1}, 1\right)$, Lemma A.2 clearly holds. Thus, we must consider the case in which $g \in G\left(\delta ; \theta_{i}, 1\right)$ and $g \notin G\left(\delta ; \theta_{1}, 1\right)$. The latter implies that the goal $g$ that is attained by worker $i$ is not attained by the weak link. Thus,

Figure A.4. (Color online) Wasted Performance of the Highest-Ability Worker Under the Optimal Goal (Left-Hand Side) and a Lower Goal (Right-Hand Side)
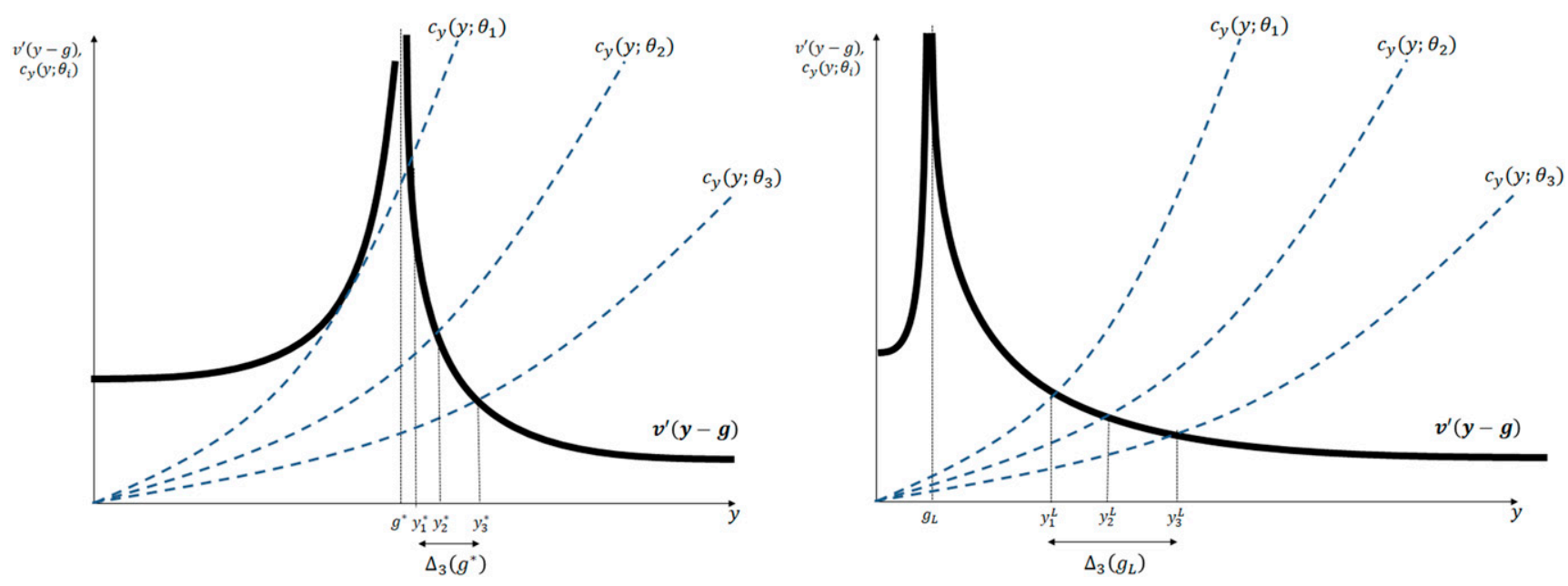
Table A.1. GMM Linear Dynamic Panel Data Model on Goals at the Group Level, Sorted by Manager Type

(1) (2)

\begin{tabular}{lcc} 
Variable & Unreasonable Manager & Reasonable Manager \\
\hline Lagged Goal & 0.0886 & 0.00141 \\
& $(0.158)$ & $(0.110)$ \\
Lagged Production & -0.0615 & $0.467^{* * *}$ \\
& $(0.339)$ & $(0.0967)$ \\
Weak-link Ability & $-4.152^{*}$ & 0.0322 \\
& $(2.108)$ & $(0.433)$ \\
High Task Ability & $5.689^{* * *}$ & 0.102 \\
& $(1.378)$ & $(0.542)$ \\
Manager Ability & 2.077 & 0.263 \\
& $(1.384)$ & $(0.152)$ \\
Round & 0.896 & 0.0174 \\
& $(0.498)$ & $(0.0742)$ \\
Constant & $-71.27^{* * *}$ & 1.858 \\
& $(21.09)$ & $(3.339)$ \\
Observations & 108 & 90
\end{tabular}

Notes. Standard errors are in parentheses. We define a reasonable manager as one who sets seven or more reasonable goals in the 10 team rounds.

$$
{ }^{*} p<0.10 ;{ }^{* * *} p<0.01 \text {. }
$$

for some $y_{1}<g, A-v^{\prime}\left(g-y_{1}\right)=c_{y}\left(y_{1} ; \theta_{1}\right)$. Hence, because $v^{\prime}\left(g-y_{1}\right)<0$, for $\lambda>1, A-\lambda v^{\prime}\left(g-y_{1}\right)>c_{y}\left(y_{1} ; \theta_{1}\right)$. Therefore, when $\lambda>1$, the production of the weak link $y_{1}$ is higher than when $\lambda=1$; for a sufficiently high $\lambda$, it must be the case that $y_{1}>g$, so $A+v^{\prime}\left(y_{1}-g\right)=c_{y}\left(y_{1} ; \theta_{1}\right)$.

Lemma A.2 indicates that a loss-averse weak-link worker is willing to just attain a goal that a higherability worker without loss aversion also attains, as long as loss aversion is sufficiently high.

Proposition 4 is a direct consequence of this result (piling up). When workers are below their goals, they receive high benefits from removing a "loss," and these incentives increase with the level of loss aversion. However, once they reach their goal and enter the domain of gains, the marginal benefits of additional performance will be substantially smaller. The optimal goal that we described in Proposition $3(b), g^{*}$, is the maximum goal that the weak-link worker is willing and able to attain; given this goal, the weak-link worker exceeds the goal by a small margin (see Figure A.2). However, if the goal is any higher- $\hat{g}=g^{*}+\varepsilon$ for an arbitrarily small $\varepsilon$-his or her performance would be substantially lower (see Figure A.1), increasing the difference in performance between high-ability workers and the weak link (wasted performance) $\Delta_{i}(g)$. To illustrate, consider an example where $n=3$ and $L\left(\theta_{1}, g\right)=\{1\}$. Thus, there are three workers: the weak link and two higher-ability workers who produce above the weak link's level in equilibrium. Figure A.3 shows the case in which the goal is higher than the optimal goal $g_{H}>g^{*}$. In this case, the weak-link worker does not meet the goal $g_{H}$, and the wasted performance of the highest-ability worker is higher than with the optimal goal $\Delta_{3}\left(g_{H}\right)>\Delta_{3}\left(g^{*}\right)$. Similarly, when the goal is less than $g_{L}<g^{*}$, all workers exceed the goal by a generous margin, but just as in the high-goals case, wasted performance is higher than under optimal goals (see Figure A.4). Therefore, low and high goals yield the highest wasted performance of high-ability workers, whereas the optimal goal induces the lowest dispersion.

\section{References}

Ainslie G (1992) Picoeconomics: The Interaction of Successive Motivational States Within the Person (Cambridge University Press, Cambridge, UK).

Argyres N (1999) The impact of information technology on coordination: Evidence from the B-2 "Stealth" Bomber. Organ. Sci. 10(2):162-180.

Babcock L, Loewenstein G (1997) Explaining bargaining impasse: The role of self-serving bias. J. Econom. Perspect. 11(1):109-126.

Babcock L, Wang X, Loewenstein G (1996) Choosing the wrong pond: Social comparisons in negotiations that reflect a self-serving bias. Quart. J. Econom. 111(1):1-19.

Bornstein G, Gneezy U, Nagel R (2002) The effect of intergroup competition on group coordination: an experimental study. Games Econom. Behav. 41(1):1-25.

Bortolotti S, Devetag G, Ortmann A (2016) Group incentives or individual incentives? A real-effort weak-link experiment. J. Econom. Psych. 56:60-73.

Brandts J, Cooper D, Fatas E (2011) Stand by me-Help, heterogeneity, and commitment in experimental coordination games Management Sci. 62(10):2916-2936.

Camerer C (2003) Behavioral Game Theory: Experiments in Strategic Interaction (Russell Sage Foundation, New York).

Charness G, Masclet D, Villeval MC (2014) The dark side of competition for status. Management Sci. 60(1):38-55.

Chen F, Drezner Z, Ryan J, Simchi-Levi D (2000) Quantifying the bullwhip effect in a simple supply chain: The impact of forecasting, lead times, and information. Management Sci. 46(3):436-443.

Cooper R, DeJong D, Forsythe R, Ross TW (1992) Communication in coordination games. Quart. J. Econom. 107(2):739-771.

Corgnet B, Hernán-González R (2014) Don't ask me if you will not listen: The dilemma of consultative participation. Management Sci. 60(3):560-585.

Corgnet B, Gómez-Miñambres J, Hernán-González R (2015) Goal setting and monetary incentives: When large stakes are not enough. Management Sci. 61(12):2926-2944.

Corgnet B, Gómez-Miñambres J, Hernán-González R (2018) Goal setting in the principal agent model: Weak incentives for strong performance. Games Econom. Behav. 109(May):311-326.

Dalton PS, Gonzalez V, Noussair CN (2016) Self-chosen goals: Incentives and gender differences. CentER Discussion Paper 20160936, Center for Economic Research, Tilburg University, Tilburg, Netherlands.

Deci EL (1971) Effects of externally mediated rewards on intrinsic motivation. J. Personality Soc. Psych. 18(1):105-115.

Devetag G, Ortmann A (2007) Experiments in solving coordination problems. Webster M Jr, Sell J, eds. Laboratory Experiments in the Social Sciences (Elsevier, London), 407-432.

Dickinson D, Villeval MC (2008) Does monitoring decrease work effort? The complementarity between agency and crowding-out theories. Games Econom. Behav. 63(1):56-76.

Doerr K, Mitchell T, Klastorin T, Brown K (1996) Impact of material flow policies and goals on job outcomes. J. Appl. Psych. 81(2): 142-152.

Falk A, Kosfeld M (2006) The hidden costs of control. Amer. Econom. Rev. 96(5):1611-1630.

Fan J, Kwasnica A, Thomas D (2018) Paying for teamwork: Supplier coordination with endogenously selected groups. Production Oper. Management 27(6):1089-1101.

Fehr E, Herz H, Wilkening T (2013) The lure of authority: Motivation and incentive effects of power. Amer. Econom. Rev. 103(4): 1325-1359. 
Frey BS, Jegen R (2001) Motivation crowding theory. J. Econom. Surveys 15(5):589-611.

Gerchak Y, Wang Y (2004) Revenue-sharing vs. wholesale-price contracts in assembly systems with random demand. Production Oper. Management 13(1):23-33.

Gill D, Prowse V (2012) A structural analysis of disappointment aversion in a real effort competition. Amer. Econom. Rev. 102(1): 469-503.

Goerg SJ, Kube S (2012) Goals (th)at work-Goals, monetary incentives, and workers' performance. MPI Collective Goods Preprint 2012/19, Max Planck Institute for Research on Collective Goods, Bonn, Germany.

Gómez-Miñambres J (2012) Motivation through goal setting. J. Econom. Psych. 33(6):1223-1239.

Heath C, Larrick R, Wu G (1999) Goals as reference points. Cognitive Psych. 38(1):79-109.

Hoffman M, Kahn LB, Li D (2018) Discretion in hiring. Quart. J. Econom. 133(2):765-800.

Hsiaw A (2013) Goal-setting and self-control. J. Econom. Theory 148(2):601-626.

Hyndman K, Kraiselburd S, Watson N (2014) Coordination in games with strategic complementarities: An experiment on fixed vs. random matching. Production Oper. Management 23(2): 221-238.

Kahneman D, Tversky A (1979) Prospect theory: An analysis of decision under risk. Econometrica 47(2):263-292.

Kamenica E (2012) Behavioral economics and psychology of incentives. Annual Rev. Econom. 4(1):427-452.

Knez M, Camerer CF (1994) Creating expectational assets in the laboratory: Coordination in weakest-link games. Strategic Management J. 15(S1):101-119.
Kosfeld M, Neckermann S (2011) Getting more work for nothing? Symbolic awards and worker performance. Amer. Econom. J. Microeconom. 3(3):86-99.

Linderman K, Schroeder RG, Choo AS (2006) Six Sigma: The role of goals in improvement teams. J. Oper. Management 24(6):779-790.

Locke E, Latham G (2002) Building a practically useful theory of goal setting and task motivation: A 35-year odyssey. Amer. Psych. 57(9):705-717.

Loewenstein G, Issacharoff S, Camerer C, Babcock L (1993) Selfserving assessments of fairness and pretrial bargaining. J. Legal Stud. 22(1):135-159.

Shokoohyar S, Qi A, Katok E (2017) Project management under risksharing contracts. Working paper, University of Texas at Dallas, Richardson.

Smith V (1976) Experimental economics: Induced value theory. Amer. Econom. Rev. 66(2):274-279.

Smithers S (2015) Goals, motivation and gender. Econom. Lett. 131(June):75-77.

Sterman J (1989) Modeling managerial behavior: Misperceptions of feedback in a dynamic decision making experiment. Management Sci. 35(3):321-339.

Van Huyck JB, Battalio RC, Beil RO (1990) Tacit coordination games, strategic uncertainty, and coordination failure. Amer. Econom. Rev. 80(1):234-248.

Vranceanu R, El Ouardighi F, Dubart D (2015) Team production with punishment option: Insights from a real-effort experiment. Management Decision Econom. 36(6):408-420.

Weber RA (2006) Managing growth to achieve efficient coordination in large groups. Amer. Econom. Rev. 96(1):114-126.

Wu G, Heath C, Larrick R (2008) A prospect theory model of goal behavior. Working paper, University of Chicago, Chicago. 